\title{
Pasado, presente y futuro de la enseñanza universitaria del ciberperiodismo: métodos y tendencias
}

\section{The past, present, and future of university teaching of online journalism: methods and trends}

\author{
Pere Masip; Xosé López-García; Javier Díaz-Noci; Bella Palomo; Ramón Salaverría; \\ Koldobika Meso-Ayerdi
}

Cómo citar este artículo:

Masip, Pere; López-García, Xosé; Díaz-Noci, Javier; Palomo, Bella; Salaverría, Ramón; Meso-Ayerdi, Koldobika (2022). "Pasado, presente y futuro de la enseñanza universitaria del ciberperiodismo: métodos y tendencias". Profesional de la información, v. 31, n. 1, e310101.

https://doi.org/10.3145/epi.2022.ene.01

Artículo recibido el 09-07-2021 Aceptación definitiva: 22-11-2021

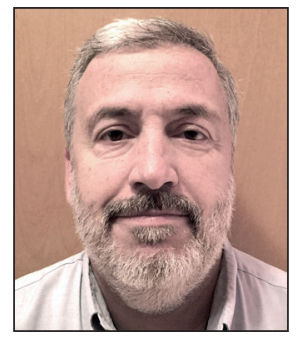

Pere Masip ${ }^{1}$

https://orcid.org/0000-0002-8231-0824

Universitat Ramon Llull

Facultat de Comunicació i Relacions

Internacionals Blanquerna

Plaça Joan Corominas, $s / n$

08001 Barcelona, España

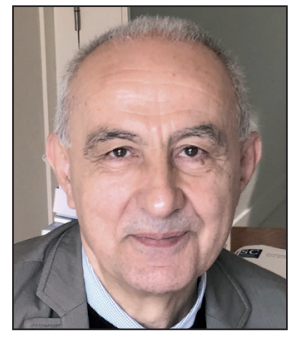

Xosé López-García

https://orcid.org/0000-0002-1873-8260

Universidad de Santiago de Compostela

Departamento de Ciencias de la

Comunicación

Avenida de Castelao, $\mathrm{s} / \mathrm{n}$

15782 Santiago de Compostela, España

xose.lopez.garcia@usc.es

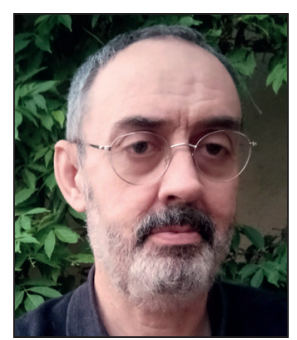

Javier Díaz-Noci $\square$

https://orcid.org/0000-0001-9559-4283

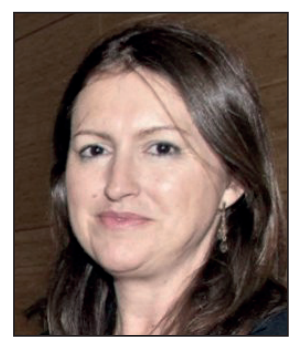

\section{Bella Palomo}

https://orcid.org/0000-0003-2228-5716

Universidad Pompeu Fabra

Departamento de Comunicación

Roc Boronat, 138

08018 Barcelona, España

javier.diaz@upf.edu

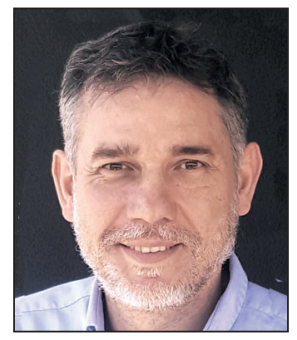
Ramón Salaverría
https://orcid.org/0000-0002-4188-7811
Universidad de Navarra
Facultad de Comunicación
Campus Universitario
31009 Pamplona, España
rsalaver@unav.es

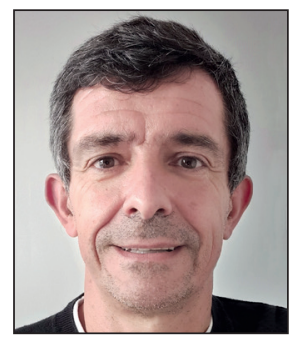

Universidad de Málaga

Facultad de Ciencias de la Comunicación

Departamento de Periodismo

Campus de Teatinos, $\mathrm{s} / \mathrm{n}$

29071 Málaga, España

bellapalomo@uma.es

Koldobika Meso-Ayerdi

https://orcid.org/0000-0002-0400-133X

Universidad del País Vasco/Euskal Herriko Unibertsitatea

Departamento de Periodismo

Barrio Sarriena, $\mathrm{s} / \mathrm{n}$

48940 Leioa (Bizkaia), España

koldo.meso@ehu.eus

\section{Resumen}

La enseñanza universitaria en España del periodismo digital, o ciberperiodismo, ha llegado para quedarse. Desde que, a mediados de los años 1990, se incorporaron las primeras materias sobre esta disciplina en los planes de estudios, hasta el comienzo de la década de 2020, cuando el número de asignaturas supera el centenar, se ha recorrido un largo camino, que ha conducido a la consolidación de esta especialidad. A partir de una revisión documental de los programas docentes de todas las asignaturas vinculadas al ciberperiodismo $(n=119)$ publicados online por las universidades españolas, así como de una encuesta a sus docentes $(n=51)$, este estudio revela el perfil de la enseñanza en torno al periodismo digital en España. Los resultados confirman la relevancia y el fortalecimiento académico de la disciplina, aunque ponen de manifiesto asimismo las dificultades de los docentes para mantener sus asignaturas actualizadas, en un contexto de rápidos y continuos cambios en la profesión periodística. 


\title{
Palabras clave
}

Ciberperiodismo; Periodismo digital; Periodismo; Cibermedios; Medios online; Enseñanza; Planes de estudio; Métodos docentes; Innovación; Universidad; España.

\begin{abstract}
Teaching of digital journalism, or cyberjournalism, in Spanish universities is here to stay. Its long development since the first courses in this discipline were added to college curricula in the mid-1990s until the beginning of the 2020s, when the number of such courses exceeds 100 , has led to the consolidation of this specialty. Based on a review of the syllabi of all courses related to cyberjournalism $(n=119)$ published online by Spanish universities, as well as a survey of their teachers $(n=51)$, the results of this study depicts the profile of teaching about digital journalism in Spain. The results confirm the relevance and academic strength of this discipline, albeit also revealing the difficulties faced by teachers in keeping their courses up to date in a context of rapid and continuous change in the journalistic profession.
\end{abstract}

\section{Keywords}

Cyberjournalism; Digital journalism; Online journalism; Journalism; Cybermedia; Teaching; Syllabus; Teaching methods; Innovation; University; Spain.

\section{Financiación}

Este trabajo ha sido subvencionado por el Ministerio de Ciencia e Innovación de España mediante los proyectos RTI2018-095775-B-C41, RTI2018-095775-B-C43, RTI2018-095775-B-C44, RTI2018-093346-B-C31, RTI2018093346-B-C33 y PID2019-108956RB-I00, cofinanciados por el Fondo Europeo de Desarrollo Regional (Feder).

\section{Introducción}

A mediados de los años 1990, cuando apenas una veintena de universidades españolas ofrecía estudios sobre Comunicación (Murciano-Martínez, 2005), comenzó la andadura de la enseñanza universitaria del ciberperiodismo. No lo hizo con ese nombre, sino con otros como "periodismo electrónico" (Armañanzas; Díaz-Noci; Meso-Ayerdi, 1996), "periodismo online" (Pérez-Luque; Perea-Foronda, 1997) o "periodismo en internet" (Díaz-Noci; Meso-Ayerdi, 1999). Cualquiera que fuera la denominación elegida, lo cierto es que un puñado de universidades incorporó a sus planes de estudios la enseñanza sobre las expresiones digitales del periodismo, recién aparecidas en los países tecnológicamente más avanzados (Carlson, 2003). De hecho, la primera asignatura universitaria en España sobre ciberperiodismo, ofrecida por la Universidad de Navarra en el curso 1994-1995, coincidió en el tiempo con la aparición de los primeros medios digitales en el país (Salaverría, 2016). Cumplido el primer cuarto de siglo desde la aparición de los primeros cursos sobre esta disciplina, este artículo revisa su evolución y radiografía el panorama actual, explorando desafíos futuros a través de las percepciones de los docentes.

A partir de un repaso a los primeros veinticinco años de enseñanzas sobre periodismo digital, este trabajo presenta un análisis sobre el perfil académico actual de esta disciplina. Para ello, se ha consultado a docentes de la asignatura de ciberperiodismo y de materias directamente relacionadas, las que enseñan destrezas digitales de la actividad periodística, en universidades de toda España. Junto con un balance sobre los desarrollos alcanzados, este artículo perfila el estado actual de la docencia del ciberperiodismo en el sistema universitario español y, paralelamente, subraya las fortalezas y debilidades de esta disciplina a juicio de sus docentes. Con base en las interpretaciones del profesorado, este estudio evalúa, en definitiva, el perfil y las tendencias de evolución de la docencia del ciberperiodismo en España.

Con anterioridad a este estudio, otros trabajos han examinado la evolución de la investigación sobre la disciplina del ciberperiodismo en España (Masip; Micó-Sanz, 2010; Salaverría, 2019). Ha habido, asimismo, estudios sobre el perfil de las enseñanzas en torno a esta materia (Tejedor-Calvo, 2007; Sánchez-García, 2017; 2021). Sin embargo, hasta ahora ninguna de esas revisiones ha recabado las opiniones de los propios docentes de la disciplina, con el fin de realizar una autoevaluación sobre las aportaciones y los desafíos pendientes en la docencia universitaria del ciberperiodismo en España.

\subsection{Origen del ciberperiodismo y su enseñanza en España}

Los primeros ejemplos de enseñanza del periodismo digital en la universidad española fueron prácticamente simultáneos a la aparición de los primeros medios digitales. En Estados Unidos, los antecedentes de los cibermedios se sitúan en las últimas décadas del siglo XX, cuando las experiencias electrónicas presagiaban cambios mayores que desembocaron en la World Wide Web. Grupos empresariales como Knight-Ridder apostaron por la investigación y la innovación, y plantearon que los contenidos periodísticos se visualizarían mediante dispositivos móviles. Roger Fidler, quien llevaba 
al menos desde 1981 trabajando estos temas (Fidler, 1981), imaginó una tableta plana (flat panel) que nunca llegó a desarrollarse (Díaz-Noci, 1994; Brainard, 2010).

Las experiencias de periodismo electrónico se multiplicaron en varios países, hasta que, con la invención en 1989 de la World Wide Web por Tim Berners-Lee, el periodismo del ciberespacio emergió definitivamente en 1994 para imponerse a todos estos servicios (Armañanzas; Díaz-Noci; Meso-Ayerdi, 1996; Díaz-Noci, 2005). La red informática mundial provocó en poco tiempo una verdadera eclosión de "periódicos online" (Pérez-Luque; Perea-Foronda, 1997) que buscaban su propio lenguaje multimedia, su propia identidad y la emancipación de sus "padres" impresos y audiovisuales (Díaz-Noci; Meso-Ayerdi, 1998).

En España, los medios digitales también comenzaron su expansión. En 1994 la revista El temps (Valencia) migró a la red (Díaz-Noci; Meso-Ayerdi, 1999), y le siguieron El periódico de Catalunya (Barcelona) y El mundo (Madrid), lanzando sendas versiones de sus diarios en la red Servicom, al tiempo que experimentaban con otro soporte de distribución digital para sus noticias, el cd-rom (Salaverría, 2016). Al año siguiente, comenzó un goteo de nuevas publicaciones web, con periódicos como El comercio (Gijón), Avui (Barcelona), Diari de Mallorca, La vanguardia (Barcelona), El diario vasco (San Sebastián) y $A B C$ (Madrid), por este orden (Masip; Micó-Sanz, 2010; Salaverría, 2016). En el ámbito académico, en 1996 se publicó la que se puede considerar primera monografía exclusivamente dedicada al periodismo online (Armañanzas; Díaz-Noci; Meso-Ayerdi, 1996) y se inició una fructífera senda investigadora que, en poco tiempo, aportó una intensa producción científica con la mirada puesta en lo que estaba ocurriendo en la proximidad y con atención a lo que ocurría en otros países, lo que incentivó una rápida internacionalización (Palomo, 2004; Salaverría, 2019; Larrondo-Ureta; Canavilhas; Fernandes-Teixeira; Luiz-Martins; Meso-Ayerdi; Pérez-Dasilva; Peña-Fernández; Zamith, 2020).

\subsection{Evolución de la docencia del ciberperiodismo (1994-2020)}

Mientras los cibermedios españoles consumían las primeras etapas de su historia en internet (Díaz-Noci, 2012), los centros de formación de periodistas, que durante esa última década del pasado siglo iniciaban una etapa de expansión (Murciano-Martínez, 2005), introducían esas novedades en materias sobre tecnologías de la comunicación y sobre los nuevos soportes. Mientras en varias universidades -País Vasco, Complutense, Navarra o Santiago de Compostela, entre otras- surgían investigadores individuales o en grupo dedicados a estudiar la naciente información periodística en internet, aparecieron también las primeras asignaturas dedicadas a enseñar esa disciplina.

A mediados de la década de 1990, coincidiendo con el arranque de los primeros cibermedios en España -como hemos dicho-, algunas universidades españolas vieron la necesidad de incluir, de la forma que en aquel momento se podía, la enseñanza de este cuarto medio de comunicación, junto con la prensa, la radio y la televisión. Además de enriquecer asignaturas previas con contenidos digitales, se crearon algunas materias específicas. En la Universidad de Navarra desde el curso 1994-1995 se utilizó la asignatura 'Tecnología de la información', de la que era entonces responsable María-José Pérez-Luque, ingeniera de telecomunicaciones. Esta profesora creó a su vez en ese mismo curso junto con Noelia Fernández-Arroyo, recién graduada en Periodismo, el MMLab - Laboratorio de Comunicación Multimedia (Salaverría, 2009). En la Universidad del País Vasco, Javier Díaz-Noci y Koldo Meso-Ayerdi propusieron la creación de una asignatura de libre elección sobre 'Periodismo en Internet', a partir del curso 1997-1998, que luego se ofreció en una versión optativa en el Campus Virtual de la misma Universidad, a partir del curso 1999-2000. Por su parte, la Universidad de Málaga integró en su primer plan de estudios la asignatura optativa 'Nuevas tecnologías informativas', impartida desde el curso 1995-96, con el fin de abordar los avances en la digitalización de la información; cuatro cursos más tarde, la asignatura cambió su nombre a 'Periodismo interactivo y creación de medios digitales', siempre bajo la coordinación de Bella Palomo. La Universitat Pompeu Fabra, a iniciativa de Joan-Francesc Cànovas, periodista en ejercicio, también comenzó a ofrecer una asignatura optativa ('Periodismo en Internet'), ya consolidada en 1999, y la Universidad de Santiago de Compostela, con Xosé López-García al frente, hizo lo propio al incorporar en el plan de estudios de 1993 -el primero de estos estudios en Compostela- una materia sobre 'Información y nuevos soportes'; posteriormente, en la actualización del plan de estudios de 1999, introdujo una orientación en la licenciatura que se denominó 'Periodismo electrónico y multimedia', con cinco materias específicas ('Periodismo electrónico', 'Creación de productos para la red', 'Lenguaje y guion multimedia', 'Sistemas e innovaciones tecnológicas' y 'Taller de aplicaciones en la red'). A comienzos del siglo XXI, prácticamente todos los centros universitarios españoles con carreras de Periodismo fueron incorporando asignaturas directamente relacionadas con el tema (Tejedor-Calvo, 2007). Esas materias componen el corpus estudiado en este artículo.

Vale la pena detenerse un tanto en el contexto europeo. La historia de la formación de los periodistas en el campo digital en Europa recorrió un camino similar al descrito en España. El punto de partida de la incorporación de la dimensión digital en la formación periodística lo fijó la declaración de Bolonia del año 1999 -acuerdo de los ministros de Educación de varios países europeos-, que trazó la ruta para la construcción del Espacio Europeo de Educación Superior (EEES). Esta reforma permitió a las universidades europeas emprender un proceso de adaptación y transformación de sus planes de estudio. En este contexto, la mayoría de los países inició la adaptación de sus respectivos sistemas universitarios, abriendo paso así a una nueva etapa en los estudios de Comunicación en general, y de Periodismo en particular.

A partir de 2000, numerosos investigadores europeos e iberoamericanos introdujeron reflexiones sobre el prisma digital, sobre el periodismo digital y sobre su enseñanza en las universidades europeas y latinoamericanas (López-García, 2010). 
Consolidado el conocido como "modelo europeo", los primeros estudios sobre la reformada formación de los periodistas mostraron que los planes de formación habían comenzado a incluir la tecnología digital como una cuestión transversal en el campo comunicativo, al tiempo que se creaban materias específicas. En el territorio ibérico, el panorama de la enseñanza periodística
La atención a la formación en periodismo digital es manifiesta en las universidades del Sur y del Norte de Europa, tras comprobarse que no era el fin del periodismo sino el inicio de una nueva etapa

"discurre por diferentes vicisitudes que, principalmente, se resumen en tres aspectos: aumento exponencial de los centros que ofrecen la titulación, cambios de contenidos progresivos, y adaptación educativa al Espacio Europeo de Educación Superior (EEES) desde 2007 en Portugal y 2010 en España” (Marinho; Sánchez-García, 2020).

La atención a la formación en periodismo digital también es manifiesta en las universidades del Sur y del Norte de Europa, tras comprobarse que no era el fin del periodismo sino el inicio de una nueva etapa (Oggolder; Brügger; Metyková, Salaverría; Siapera, 2020). Muchos profesionales e investigadores (García; 1998; Davenport; Beck, 2001; Katz, 1999; Boczkowski, 2004; Pavlik, 2004; Deuze, 2004, entre otros) advirtieron que las tecnologías digitales alterarían el rostro del periodismo y tendrían un fuerte impacto en la formación de los periodistas (Bierhoff; Schmidt, 1997). Varios investigadores del campo de la Comunicación avisaron asimismo sobre las transformaciones que introducía la tecnología digital en la educación de los futuros periodistas y la necesidad de tenerlas en cuenta en los planes formativos (Pavlik, 2001). La especificidad creciente del periodismo digital y el surgimiento de la primera generación de cibermedios durante la década de 1990 (Deuze, 2001) mostró que el ciberperiodismo había llegado para quedarse y que era necesario preparar adecuadamente a los futuros periodistas digitales.

Con ese contexto, la mayoría de los centros de formación en Europa y en otras regiones fomentó cambios en la formación de los periodistas. En concreto, se impulsó un gran número de cursos orientados a capacitar a los periodistas

"para trabajar en el escenario multiplataforma, controlar los procesos de producción y cubrir y editar las piezas periodísticas con herramientas actuales apropiadas para cada tipo de información" (IJIE Integrated Journalism in Europe is an Erasmus Lifelong Learning Project, 2014).

Este objetivo sigue presidiendo la renovación actual de los cursos sobre ciberperiodismo.

En España, la incorporación de las asignaturas se hizo de forma paulatina, a medida que se actualizaban planes de estudio o ciertos centros iniciaban las enseñanzas del grado de Periodismo. Así, en los planes de estudio del curso 20042005 figuraba un total de 17 asignaturas vinculadas al ciberperiodismo en 15 universidades. De ellas, dos universidades ofrecían dos materias en sus respectivos programas (Tejedor-Calvo, 2006).

Con el avance de la primera década del siglo XXI, los planes de estudio incorporaron la formación multimedia y digital. Se adaptaron al modelo del EEES, que establecía el real decreto de 2007, guiados por el Libro blanco de los títulos de grado en comunicación, elaborado por la conferencia de decanos de Comunicación para la Agencia Nacional de Evaluación de la Calidad y Acreditación (Murciano-Martínez, 2005). El incremento de materias "digitales" se ha constatado a medida que se actualizaban los planes de estudio. En el curso 2020-2021, la formación en Periodismo ofrecida por las universidades españolas era cada vez más técnica y especializada, con un crecimiento lento pero progresivo de las enseñanzas relacionadas con el periodismo y la comunicación digital (Sánchez-García, 2021). Estudios previos (Palomo; Sánchez, 2014) ya adelantaron que las materias relacionadas con los procesos de interacción que fundamentan el periodismo digital se habían incrementado.

\section{Métodos}

A partir del contexto histórico descrito, este estudio explora el perfil actual en España de la docencia universitaria sobre ciberperiodismo, así como de materias próximas, mediante dos métodos de investigación complementarios:

1) un análisis documental sobre los programas docentes de las asignaturas y

2) una encuesta a su profesorado.

\subsection{Análisis documental}

En cuanto al primer método, se consultó el Registro de universidades, centros y títulos (RUCT) del Ministerio de Ciencia, Innovación y Universidades para elaborar un corpus de todas las asignaturas relacionadas con el ciberperiodismo $(n=$ 119) en el curso 2020-2021, conforme a la oferta publicada en la web por parte de las 38 facultades de Comunicación españolas, públicas y privadas, que contaban con Grados en Periodismo oficiales (ver tabla 1). Los criterios de exclusión aplicados fueron los grados de periodismo extinguidos, los grados de reciente creación en cuyos primeros cursos no se imparte ciberperiodismo, o los centros cuyas guías docentes del curso 2020-2021 no eran accesibles, quedando cinco universidades fuera del estudio (Universidad Camilo José Cela, Universidad Europea Miguel de Cervantes, Universitat de les Illes Balears, Universidad Isabel I y Universidad Tecnología y Empresa). 
En su conjunto, las 119 asignaturas que componen la muestra contaban con un profesorado conformado por 192 docentes. Fruto del rastreo realizado, se confeccionó una base de datos con los títulos de las asignaturas, su tipo (optativas u obligatorias), el curso en el que se impartían, así como su programa, normalmente dividido en competencias, habilidades, contenidos, metodología docente y bibliografía. El estudio prestó especial atención a los métodos docentes empleados. Este primer procedimiento de investigación permitió, por tanto, identificar los contenidos docentes, los métodos didácticos, la bibliografía recomendada por las asignaturas de ciberperiodismo y los responsables de su impartición.

\subsection{Encuesta al profesorado}

El segundo método consistió en una encuesta, dirigida al profesorado a cargo de las materias identificadas en la primera parte del estudio. La consulta se dirigió a los coordinadores de asignatura que facilitaban su contacto en la guía docente $(n=101)$. La consulta se realizó en junio de 2021, mediante un formulario en línea remitido a la totalidad de los docentes al frente de esas asignaturas. Para no desvirtuar los resultados, se evitó implicar al profesorado auxiliar de esas asignaturas, cuyo contacto también estaba disponible en algunos casos, por considerar que su conocimiento de la materia y, especialmente, de sus desafíos, era más limitado que el de los profesores responsables de las asignaturas. La encuesta se centró, por tanto, en las percepciones y opiniones de los docentes que coordinan asignaturas directamente relacionadas con la enseñanza del ciberperiodismo, explorando las principales fortalezas y debilidades que perciben en el presente, junto con los principales desafíos para su desarrollo futuro. Se trata, por tanto, de un estudio exploratorio, orientado a detectar tendencias en dicha enseñanza.

La encuesta fue respondida por docentes de 31 de los 38 grados analizados, participando poco más de la mitad (50,5\%) de los 101 docentes consultados $(n=51)$. Como ya hemos indicado, nuestro estudio abarca un universo de 119 asignaturas relacionadas con el ciberperiodismo. Para ese universo, el tamaño muestral óptimo habría sido de 92 respuestas, lo que habría supuesto un margen de error de $\pm 5 \%$ y un nivel de confianza del $95 \%$. El volumen de 51 respuestas alcanzado en nuestro estudio ha sido inferior a esa cifra óptima: nuestra encuesta presenta un margen de error del $\pm 10,42 \%$, para un nivel de confianza del $95 \%$. El reducido tamaño del universo estudiado nos obligaba a contar con un tamaño muestral elevado para garantizar un óptimo margen de error estadístico, umbral que lamentablemente no alcanzamos, entre otros motivos porque la encuesta solo pudo dirigirse a 101 docentes -los coordinadores de asignatura que facilitaban dirección de contacto- de un total de 119 asignaturas. En todo caso, nuestra encuesta permite obtener algunas referencias aproximadas. Asimismo, observamos que el perfil de los participantes responde a los docentes más experimentados, doctores y con puestos permanentes, y, por lo tanto, con una mayor responsabilidad en la confección de las asignaturas, mientras que fueron los profesores asociados quienes menos colaboraron en el estudio.

En cuanto a la estructura de la encuesta, se plantearon primero dos preguntas de control, para comprobar la adecuación de las respuestas a la información de que ya disponíamos gracias al primer método de este estudio (“¿En qué universidad imparte docencia? Si imparte docencia en más de una, indique en la que tiene mayor dedicación” y “¿Qué asignatura sobre periodismo digital imparte?"). Por respeto a la privacidad de los consultados, las respuestas a estas preguntas no se hacen públicas en este trabajo.

Dividida en dos partes, con preguntas tanto cerradas -a elegir entre opciones, o escalas de Likert- como abiertas - para obtener resultados más afinados-, la encuesta permitió definir el perfil de los docentes y explicar cuáles eran sus opiniones. Para agilizar el proceso de los datos, incluimos una serie de respuestas cerradas, y la posibilidad de respuesta múltiple. Las preguntas de respuesta múltiple centradas en determinar fortalezas y debilidades se limitaron a tres posibles, de manera jerarquizada, por razones de pura operatividad y de tratamiento de los resultados. En algunos campos, admitimos respuestas abiertas (por ejemplo, cuando se preguntó a los docentes por los materiales bibliográficos o las herramientas técnicas, y programas informáticos, que emplean). El cuestionario también exploró cuestiones que preocupan al cuerpo docente de la materia de cara al futuro inmediato. A esta parte prospectiva dedicamos la parte final de nuestro estudio. Finalmente, se ofreció a los participantes de la encuesta una última respuesta abierta para explicar cualquier información adicional o comentario que pudiesen hallar relevante. 
Tabla 1. Asignaturas vinculadas al ciberperiodismo en grados de periodismo en España (curso 2020-2021)

\begin{tabular}{|c|c|c|c|}
\hline Universidad & Curso & Asignatura & Tipo \\
\hline \multirow{3}{*}{$\begin{array}{l}\text { Cesag (adscrito a la Universidad Pontificia } \\
\text { Comillas) }\end{array}$} & $3^{\circ}-4^{\circ}$ & Laboratorio de Contenidos Digitales & Optativa \\
\hline & $4^{\circ}$ & Periodismo Digital & Obligatoria \\
\hline & $4^{\circ}$ & Community Management & Obligatoria \\
\hline \multirow{3}{*}{ EUSA (adscrito a la Universidad de Sevilla) } & 30 & Periodismo Multimedia y Diseño Gráfico Digital & Optativa \\
\hline & $4^{\circ}$ & Redacción Periodística en la Red & Optativa \\
\hline & $4^{\circ}$ & Innovación Cibernética en Periodismo & Optativa \\
\hline \multirow{2}{*}{ Universidad a Distancia de Madrid } & 10 & Investigación en Medios Digitales & Obligatoria \\
\hline & $4^{\circ}$ & Periodismo Digital y Redes Sociales & Optativa \\
\hline \multirow{4}{*}{ Universidad Carlos III de Madrid } & 10 & Comunicación y Participación Ciudadana en la Red & Obligatoria \\
\hline & $2^{\circ}$ & Periodismo en la Red & Obligatoria \\
\hline & $4^{\circ}$ & Periodismo de Datos & Obligatoria \\
\hline & $3^{\circ}$ y $4^{\circ}$ & Comunicación Multimedia: el Relato Periodístico & Optativa \\
\hline \multirow{2}{*}{ Universidad Católica San Antonio } & $3^{\circ}$ & Tecnología III: Multimedia Interactiva & Obligatoria \\
\hline & $4^{\circ}$ & Taller de Periodismo Multimedia & Obligatoria \\
\hline \multirow{2}{*}{ Universidad CEU Cardenal Herrera } & $4^{\circ}$ & Producción Periodística Aplicada a Internet & Obligatoria \\
\hline & $4^{\circ}$ & Comunicación Digital y Arquitectura de la Información & Obligatoria \\
\hline \multirow{2}{*}{ Universidad CEU San Pablo } & 10 & Redes Sociales & Formación básica \\
\hline & $2^{\circ}$ & Producción en Entornos Digitales & Obligatoria \\
\hline \multirow{2}{*}{ Universidad Complutense de Madrid } & $3^{\circ}$ & Multimedia & Obligatoria \\
\hline & $4^{\circ}$ & Tecnologías de la Gestión Periodística de la Información Digital & Obligatoria \\
\hline \multirow{3}{*}{ Universidad de Castilla-La Mancha } & $3^{\circ}$ & Ciberperiodismo & Obligatoria \\
\hline & $4^{\circ}$ & Taller de Periodismo Multimedia I & Optativa \\
\hline & $4^{\circ}$ & Taller de Periodismo Multimedia II & Optativa \\
\hline \multirow{3}{*}{ Universidad de Extremadura } & $3^{\circ}$ & Contenidos Digitales I & Obligatoria \\
\hline & $3^{\circ}$ & Contenidos Digitales II & Obligatoria \\
\hline & 30 & Redacción en Internet & Obligatoria \\
\hline Universidad de La Laguna & $3^{\circ}$ & Ciberperiodismo & Obligatoria \\
\hline \multirow{2}{*}{ Universidad de Málaga } & $4^{\circ}$ & Información en Internet & Optativa \\
\hline & $3^{\circ}$ & Periodismo Ciudadano y Redes Sociales & Optativa \\
\hline \multirow{2}{*}{ Universidad de Murcia } & $3^{\circ}$ & Tecnologías de la Producción Informativa & Obligatoria \\
\hline & $4^{\circ}$ & Construcción de Servicios de Información Digital & Obligatoria \\
\hline \multirow{3}{*}{ Universidad de Navarra } & $1^{\circ}$ & Comunicación Multimedia & Obligatoria \\
\hline & $3^{\circ}$ & Ciberperiodismo & Obligatoria \\
\hline & $4^{\circ}$ & Edición de Medios Digitales & Obligatoria \\
\hline \multirow{3}{*}{ Universidad de Sevilla } & $3^{\circ}$ & Periodismo Multimedia y Diseño Gráfico Digital & Optativa \\
\hline & $4^{\circ}$ & Redacción Periodística en la Red & Optativa \\
\hline & $4^{\circ}$ & Innovación Cibernética en Periodismo & Optativa \\
\hline \multirow{4}{*}{ Universidad de Valladolid } & 10 & Innovaciones Tecnológicas Aplicadas al Periodismo & Obligatoria \\
\hline & $3^{\circ}$ & Ciberperiodismo & Obligatoria \\
\hline & $3^{\circ}$ & Diseño de Páginas Web & Optativa \\
\hline & $3^{\circ}$ & Periodismo Participativo en la Red & Optativa \\
\hline \multirow{2}{*}{ Universidad de Zaragoza } & $4^{\circ}$ & Comunicación e Información Digital & Obligatoria \\
\hline & $4^{\circ}$ & Proyecto de Comunicación Digital & Obligatoria \\
\hline
\end{tabular}




\begin{tabular}{|c|c|c|c|}
\hline Universidad & Curso & Asignatura & Tipo \\
\hline \multirow{2}{*}{ Universidad del País Vasco } & $2^{\circ}$ & Redacción Ciberperiodística & Obligatoria \\
\hline & $3^{\circ}$ & Periodismo Social y Participativo en Internet & Optativa \\
\hline \multirow{7}{*}{ Universidad Europea de Madrid } & $3^{\circ}$ & Edición y Diseño Web & Obligatoria \\
\hline & $3^{\circ}$ & Marketing Digital & Obligatoria \\
\hline & $3^{\circ}$ & Periodismo Inmersivo & Obligatoria \\
\hline & $4^{\circ}$ & Infografía y Procesamiento de Datos & Optativa \\
\hline & $4^{\circ}$ & Diseño de Apps & Optativa \\
\hline & $4^{\circ}$ & Gamificación & Optativa \\
\hline & $4^{\circ}$ & Narrativa Transmedia & Optativa \\
\hline \multirow{6}{*}{ Universidad Europea del Atlántico } & 10 & Tecnologías de la Información y la Comunicación-TIC & Obligatoria \\
\hline & $2^{\circ}$ & Soportes Multimedia en la Producción Informativa & Obligatoria \\
\hline & 30 & Sociedad de la Información y del Conocimiento & Obligatoria \\
\hline & $3^{\circ}$ & Producción en Prensa y Cibermedios & Obligatoria \\
\hline & $3^{\circ}$ & Producción en Nuevos Medios y Formatos & Optativa \\
\hline & $4^{\circ}$ & Animación Digital & Optativa \\
\hline \multirow{2}{*}{ Universidad Fernando Pessoa } & $3^{\circ}$ & Nuevas Tecnologías de la Información y Producción Multimedia & Obligatoria \\
\hline & $4^{\circ}$ & Community Manager & Optativa \\
\hline \multirow{8}{*}{ Universidad Francisco de Vitoria } & 10 & Información Multimedia & Obligatoria \\
\hline & $3^{\circ}$ & Periodismo Multimedia y Nuevos Formatos & Obligatoria \\
\hline & $3^{\circ}$ & Nuevas Herramientas & Optativa \\
\hline & $4^{\circ}$ & Tratamiento de la Información y Gestión en Redes Sociales & Obligatoria \\
\hline & $4^{\circ}$ & Diseño Multimedia & Obligatoria \\
\hline & $4^{\circ}$ & Diseño Infográfico II & Optativa \\
\hline & $4^{\circ}$ & Comunicación Virtual & Optativa \\
\hline & $4^{\circ}$ & Social Media Management & Optativa \\
\hline \multirow{2}{*}{ Universidad Miguel Hernández de Elche } & $2^{\circ}$ & Comunicación Digital e Internet & Obligatoria \\
\hline & $3^{\circ}$ & Proyectos Periodísticos Especializados I & Obligatoria \\
\hline \multirow{4}{*}{ Universidad Nebrija } & 10 & Nuevas Tecnologías y Sociedad de la Información & Obligatoria \\
\hline & $3^{\circ}$ & Redacción y Edición en Medios Digitales & Obligatoria \\
\hline & $3^{\circ}$ & Diseño Web & Obligatoria \\
\hline & $4^{\circ}$ & Gestión de Comunidades Virtuales & Obligatoria \\
\hline \multirow{2}{*}{ Universidad Pontificia de Salamanca } & $3^{\circ}$ & TIC II & Obligatoria \\
\hline & $4^{\circ}$ & Periodismo Digital & Obligatoria \\
\hline \multirow{3}{*}{ Universidad Rey Juan Carlos } & 10 & Nuevas Tecnologías y Sociedad de la Información & Obligatoria \\
\hline & $3^{\circ}$ & Periodismo Multimedia & Obligatoria \\
\hline & 30 & Planificación y Desarrollo de Proyectos en Red & Obligatoria \\
\hline \multirow{4}{*}{ Universidad San Jorge } & $3^{\circ}$ & Ciberperiodismo & Obligatoria \\
\hline & $4^{\circ}$ & Redacción Periodística en Medios Digitales & Obligatoria \\
\hline & $4^{\circ}$ & Web Design & Optativa \\
\hline & $4^{\circ}$ & Comunicación Estratégica Online & Optativa \\
\hline \multirow{4}{*}{ Universidad de Santiago de Compostela } & 30 & Multimedia: Teoría, Técnica y Aplicaciones & Obligatoria \\
\hline & $4^{\circ}$ & Nuevos Formatos y Productos para la Red & Optativa \\
\hline & $4^{\circ}$ & Teoría y Análisis de los Cibermedios & Optativa \\
\hline & $4^{\circ}$ & Nuevos Soportes y Arquitectura de la Información & Optativa \\
\hline
\end{tabular}




\begin{tabular}{|c|c|c|c|}
\hline Universidad & Curso & Asignatura & Tipo \\
\hline \multirow{4}{*}{ Universitat Autònoma de Barcelona } & $3^{\circ}$ y $4^{\circ}$ & Gestión de Contenidos Digitales & Optativa \\
\hline & $3^{\circ}$ y $4^{\circ}$ & Producción Periodística Multiplataforma & Optativa \\
\hline & $3^{\circ}$ y $4^{\circ}$ & Tendencias de Desarrollo de Internet & Optativa \\
\hline & $3^{\circ}$ y $4^{\circ}$ & Gestión de Contenidos Digitales & Optativa \\
\hline \multirow{4}{*}{ Universitat CEU Abat Oliva } & 10 & Periodismo Lab: Redacciones integrales & Obligatoria \\
\hline & $3^{\circ}$ & Technological Innovations in Journalism & Obligatoria \\
\hline & $3^{\circ}$ & Journalistic Production & Obligatoria \\
\hline & $4^{\circ}$ & Multimedia Journalism & Obligatoria \\
\hline \multirow{7}{*}{ Universitat de Lleida } & 10 & Introducción a las TIC. Periodismo & Obligatoria \\
\hline & 10 & Análisis y Creación de Contenidos en Red & Obligatoria \\
\hline & $3^{\circ}$ & Géneros y Formatos para Internet y Nuevas Plataformas & Optativa \\
\hline & $3^{\circ}$ & Periodismo Digital & Optativa \\
\hline & $3^{\circ}$ & Narrativa Interactiva & Optativa \\
\hline & $4^{\circ}$ & Introducción a la Programación Web & Optativa \\
\hline & $4^{\circ}$ & Taller de Creación Multimedia & Optativa \\
\hline Universitat de València & $2^{\circ}$ & Periodismo Digital & Obligatoria \\
\hline \multirow{4}{*}{ Universitat de Vic } & 10 & Fundamentos del Periodismo Digital & Obligatoria \\
\hline & $3^{\circ}$ & Comunicación Digital Interactiva & Obligatoria \\
\hline & $3^{\circ}$ & Taller de Comunicación Interactiva & Obligatoria \\
\hline & $3^{\circ}$ & Taller de Periodismo Digital & Obligatoria \\
\hline \multirow{3}{*}{ Universitat Internacional de Catalunya } & $3^{\circ}$ & Proyectos Periodísticos en Red & Obligatoria \\
\hline & $4^{\circ}$ & Análisis de Audiencias & Obligatoria \\
\hline & $4^{\circ}$ & Gestión de Comunidades Online & Obligatoria \\
\hline Universitat Jaume I & $3^{\circ}$ & Ciberperiodismo & Obligatoria \\
\hline \multirow{4}{*}{ Universitat Pompeu Fabra } & $2^{\circ}$ & Teoría y Técnicas del Periodismo en Internet & Obligatoria \\
\hline & $3^{\circ}$ & Taller de Periodismo Integrado & Obligatoria \\
\hline & $3^{\circ}-4^{\circ}$ & Analysing Digital Journalism & Optativa \\
\hline & $3^{\circ}-4^{\circ}$ & Periodisme de Dades i Visualització de la Informació & Optativa \\
\hline \multirow{2}{*}{ Universitat Ramon Llull } & $3^{\circ}$ & Nuevos Medios & Obligatoria \\
\hline & $3^{\circ}$ & Gestión de Contenidos Digitales & Obligatoria \\
\hline \multirow{3}{*}{ Universitat Rovira i Virgili } & $2^{\circ}$ & Diseño Gráfico y Multimedia & Obligatoria \\
\hline & $3^{\circ}$ & Periodismo en Internet & Obligatoria \\
\hline & $4^{\circ}$ & Producción de Proyectos Multimedia & Optativa \\
\hline
\end{tabular}

\section{Resultados}

\subsection{Perfil del profesorado y de las asignaturas}

Superada la etapa inicial de descubrimiento de las dimensiones digitales del Periodismo, en el comienzo de la década de 2020 las facultades de Comunicación españolas y sus docentes han normalizado la formación en torno a esos fenómenos y destrezas profesionales. Se trata de conocimientos que se han ido sedimentando con el tiempo, hasta consolidar un perfil reconocible de las asignaturas sobre ciberperiodismo en los últimos veinticinco años.

De entrada, el volumen del profesorado que enseña ciberperiodismo es muy estimable: para este estudio hemos identificado 192 docentes. Este profesorado mostraba un razonable equilibrio de género, con un $56,8 \%$ de hombres y un $43,2 \%$ de mujeres.

Nuestra encuesta dibuja un perfil de profesorado con un alto nivel de consolidación académica: se trata mayoritariamente de doctores (un $84 \%$ de quienes han respondido la encuesta lo son), con una antigüedad en el título de

El perfil del profesorado muestra un alto nivel de consolidación académica, con un grado muy alto de doctores y de participación en el diseño de las materias 
más de cinco años (un $82 \%$ de ese colectivo). Por tanto, se trata de materias coordinadas por académicos, más que por docentes no especializados. Además, la gran mayoría de quienes han respondido asegura tener un muy alto grado de participación (medido en una escala del 1 al 5) en el diseño de sus asignaturas (ver tabla 2).

El peso de los docentes que se atribuyen una mayor responsabilidad en el diseño de las asignaturas domina claramente en las respuestas. Casi tres cuartas partes de los docentes sondeados aseguran tener un nivel muy alto de intervención en los contenidos de las materias (se empleó una escala de Likert del 1 al 5, siendo 1 ninguna y 5 mucha participación), y un $18 \%$ indicó que se trata de una participación alta en el diseño del programa. En total, un $86 \%$ de los docentes interviene muy activamente en la concepción de la asignatura, y un $8 \%$ adicional se sitúa en una participación mediana. Solo un docente, que lleva escaso tiempo impartiendo la asignatura, optativa, ha reconocido tener una participación muy baja o nula en el diseño del programa.

Tabla 2. Grado de participación del profesorado en el diseño de la asignatura $(n=51)$

\begin{tabular}{|l|c|c|}
\hline & No de docentes & \% \\
\hline Ninguna participación & 1 & 2 \\
\hline Poca participación & 0 & 0 \\
\hline Moderada participación & 4 & 8 \\
\hline Bastante participación & 9 & 18 \\
\hline Mucha participación & 35 & 68 \\
\hline NS/NC & 2 & 4 \\
\hline
\end{tabular}

Tabla 3. Tipo de asignatura por curso

\begin{tabular}{|l|c|c|c|c|}
\cline { 2 - 5 } \multicolumn{1}{c|}{} & Obligatorias & Optativas & Básica & Totales \\
\hline $1^{\circ}$ curso & 12 & 0 & 1 & 13 \\
\hline $2^{\circ}$ curso & 8 & 0 & 0 & 8 \\
\hline $3^{\circ}$ curso & 36 & 11 & - & 47 \\
\hline $4^{\circ}$ curso & 19 & 25 & - & 44 \\
\hline $3^{\circ}$ y $4^{\circ}$ & 0 & 7 & - & 7 \\
\hline Totales & 75 & 43 & 1 & 119 \\
\hline
\end{tabular}

Otro dato que nos ha parecido relevante sobre el perfil de los encuestados es su vinculación contractual con la universidad. La mayoría, un 59\%, son contratados. No hemos entrado en mayores precisiones, ya que actualmente la universidad española dispone de múltiples figuras contractuales, desde las más estables o indefinidas -ayudantes, ayudantes doctores y contratados doctores, y sus equivalentes, a veces con otra terminología, en el nivel autonómico-, hasta las de profesor asociado, figura, con la ley en la mano, destinada a la contratación de profesionales de reconocido prestigio -en el periodismo digital, en el caso que examinamos- normalmente, aunque existen excepciones, sin responsabilidad en el diseño de la asignatura. Asimismo, todo el profesorado de las universidades privadas es contratado y no funcionario. El grado de respuesta del profesorado de universidades privadas ha sido alto (43\%). Por lo tanto, el $41 \%$ de funcionarios (titulares o catedráticos de universidad) de los docentes consultados es un número elevado, porque corresponde a un peso del $57 \%$ de universidades públicas en nuestra encuesta.

El $88 \%$ de los docentes que han respondido la encuesta tiene asignada su docencia en los cursos más avanzados del grado, lo que se aproxima a lo reflejado en la tabla 3, donde 98 de las 119 asignaturas $(82,4 \%)$ se imparten en 3으 y 4 으 curso. Este dato nos indica que se tiende a considerar, por parte de quienes diseñan los planes de estudio, que, al contrario de lo que ocurre con asignaturas relacionadas con la práctica del periodismo en prensa impresa -el medio históricamente originario; después vinieron la radio, la televisión e internet-, para enseñar el oficio de periodista digital hacen falta conocimientos previos. Se perfila así un escenario donde el ciberperiodismo se concibe como una materia destinada a estudiantes experimentados, no noveles, probablemente también porque, debido a su esencia multimedia, el alumnado necesita conocimientos sobre lenguaje escrito y audiovisual, y esas habilidades se adquieren en los cursos previos.

De los 119 programas docentes recogidos en nuestro corpus, 75 (63,03\%) corresponden a asignaturas obligatorias, 43 $(36,13 \%)$ a optativas y una a formación básica $(0,84 \%)$. La mayor parte del profesorado que ha respondido el cuestionario imparte docencia en asignaturas obligatorias, en concreto, un $71 \%$. Por tanto, menos de una tercera parte (29\%) de las respuestas proceden de responsables de contenidos optativos. Esto introduce un cierto sesgo, ciertamente, aunque no está muy lejano, en realidad, del peso de cada tipo de asignatura.

Aplicando una visión longitudinal, se observa un crecimiento rápido en el número de asignaturas. En el curso 2020-2021, la cantidad de cursos sobre ciberperiodismo se ha incrementado un 32,5\%, en comparación con lo recogido en los planes de estudios de cinco años atrás (Palomo, 2017). Al comienzo de la década de 2020, cada grado de Periodismo realiza una oferta media de tres asignaturas relacionadas directamente con el ejercicio de la actividad profesional en internet. Este dato no solo implica una consolidación de la enseñanza del periodismo digital, sino también la revalorización de una especialidad optativa y menor, reservada a los últimos cursos de la titulación. En el curso 2020-2021, el 63,03\% de las asignaturas relacionadas con el periodismo digital eran obligatorias; y aunque el $48 \%$ se impartía en tercer curso (36), 14 materias estaban contempladas ya en primer curso, para aproximar la dimensión digital a la formación básica de todo futuro periodista. Las universidades privadas han detectado una oportunidad distintiva en este ámbito, apostando por una media de cuatro obligatorias para abordar la redacción y edición en medios digitales, la gestión de redes sociales, el diseño web o la creación de proyectos periodísticos digitales. En el polo opuesto, solo en cuatro universidades del territorio español (EUSA, Universidad de Málaga, Universidad de Sevilla y Universidad a Distancia de Madrid) este tipo de contenidos se sigue ofreciendo apenas como materia optativa para los estudiantes.

Por otra parte, se advierte que la multiplicación de materias digitales ha favorecido la diversificación no solo de sus contenidos, sino también de su nomenclatura. Apenas un $15,13 \%$ de las asignaturas registradas para este estudio cuen- 
tan con la expresión "periodismo digital" o "ciberperiodismo" en su denominación, mientras que un 16,81\% prefiere destacar su dimensión "multimedia".

Se detectan tres tendencias en la estructura y contenidos de estas asignaturas:

- En primer lugar, las que proponen una aproximación más teórica, basada en un recorrido global por la evolución histórica de los principales hitos técnicos que han acompañado a los medios digitales hasta la actualidad.

- En segundo lugar, las asignaturas que apuestan por un enfoque más práctico, creando proyectos multimedia que simulan la actividad profesional.

- Finalmente, las materias que se nutren de enfoques especializados, ligados a nuevas salidas profesionales, como el periodismo de datos, la gestión de información en redes sociales o la programación web.

En cuanto al sistema de evaluación, de acuerdo con las guías docentes, solo 24 de las 119 asignaturas permiten ser superadas exclusivamente con proyectos prácticos, por lo que los exámenes siguen vigentes en el 79,83\% de los casos. El $11,75 \%$ de las materias analizadas cuentan con pruebas teórico-prácticas, y, en general, el peso asignado al examen oscila entre un $5 \%$ y un $70 \%$, aunque la media se sitúa en el $40 \%$. Esta defensa de la teoría entra en cierta contradicción con la bibliografía recomendada en las guías docentes, que se reduce a menos de 5 lecturas en el 38\% de los casos, y solo en el $52,7 \%$ se han actualizado las referencias en dichas guías docentes incorporando algún título de los últimos cuatro años, predominando siempre los libros sobre las revistas científicas.

El rol activo del estudiante resulta clave en un proceso de aprendizaje basado en la ejecución de proyectos y en el aprendizaje basado en proyectos, donde el aula se transforma en un laboratorio abierto a la experimentación

El rol activo del estudiante resulta clave en un proceso de aprendizaje horizontal, basado en la ejecución de proyectos y la estrategia de "aprender haciendo" o ABP (aprendizaje basado en proyectos), donde el aula se transforma en un laboratorio abierto a la experimentación (Sánchez-Duarte; Fernández-Romero, 2015), aunque exista resistencia a renunciar al examen. De hecho,

"el ABP es la metodología en la que se sustenta la generalidad de las asignaturas sobre ciberperiodismo en el ámbito iberoamericano, a partir del desarrollo de proyectos periodísticos en profundidad de carácter multimedia y transmedia" (Larrondo-Ureta et al., 2020, p. 39).

Los proyectos solicitados están orientados a la adquisición de competencias profesionales actuales -en algunos casos a través del mantenimiento de cibermedios (Martínez-Arias; Parra-Valcarce, 2020)- y al refuerzo de las que poseen un carácter básico y transversal, como la estimulación del pensamiento creativo e innovador. De hecho, muchos de los contenidos teórico-prácticos de las asignaturas de ciberperiodismo buscan potenciar competencias necesarias para elaborar mensajes adaptados a las características y la potencialidad de la web, producen contenidos en tiempo real y utilizan fórmulas colaborativas para el desarrollo de proyectos ciberperiodísticos (Larrondo-Ureta et al., 2020, p. 40).

La metodología de aprendizaje orientado a proyectos, en ocasiones combinada con la flipped classroom o metodología docente inversa, refuerza aspectos pedagógicos como la responsabilidad del alumnado, la capacidad de coordinación, colaboración y cooperación de los grupos configurados. En las asignaturas de ciberperiodismo examinadas, el alumnado con frecuencia propone el tema sobre el que versará su proyecto. En ocasiones, la labor del alumnado consiste en crear y mantener un medio de comunicación durante el tiempo que dura la asignatura; de ahí también la frecuencia en el uso de sistemas de gestión de contenidos de libre acceso y fácil gestión, como Wordpress, Blogger o Wix. Esta metodología docente estimula la colaboración entre quienes llevan a cabo el proyecto (el alumnado) y quienes lo coordinan (el profesorado), convirtiendo el proceso de aprendizaje y su supervisión en una actividad personalizada.

Junto al aprendizaje centrado en proyectos, presente en el $98 \%$ de los programas docentes consultados, otra metodología docente destacable es el aprendizaje basado en problemas, ya que aparece en 18 de las 119 asignaturas recogidas, algo más del $15 \%$ del total. La gran ventaja de esta metodología es que no se basa en la simple memorización de contenidos, sino que se centra en la adquisición de destrezas técnicas e intelectuales, mediante la resolución de problemas de orden práctico.

\subsection{Percepciones del profesorado}

Por lo que respecta a las percepciones del profesorado en torno a la materia de ciberperiodismo y sus aledañas, hay coincidencia mayoritaria en señalar que se trata de asignaturas que suscitan un interés medio-alto en el alumnado. Para obtener un análisis más preciso, tendríamos que acceder a las encuestas de satisfacción del alumnado, pero es prácticamente imposible disponer de esa información por motivos de confidencialidad, de forma que no tenemos otro medio posible de obtener alguna información que preguntar a los docentes, aplicando obligadas reservas. En todo caso, puesto que se trata de medir percepciones de los docentes, se les sondeó mediante una escala de Likert del 1 al 5, donde los docentes asignaron valores entre el 3 y el 5 , y ninguno consideró que su asignatura careciera de interés para los alumnos. Los valores más altos ( 4 y 5 ) suman nada menos que un $86 \%$ de las respuestas, y un tercio del total corresponde a la percepción por parte del profesorado de un muy alto nivel de interés entre sus estudiantes. 
Curiosamente, los propios docentes, entre los que predominan los doctores de larga trayectoria, consideran que es una fortaleza de la asignatura disponer de profesores profesionalmente muy capacitados (un $17 \%$ de las respuestas así lo indican), pero no tanto contar con profesores bien formados académicamente (solo dos respuestas lo avalan). Es decir, en opinión de los docentes, se trata de asignaturas que deberían estar enfocadas al futuro ejercicio profesional y a formar periodistas digitales. Otras características han obtenido un nivel de respuesta muy bajo: apenas un docente sitúa entre las principales fortalezas de la materia la simulación profesional, si bien, examinando los programas de las asignaturas, sí es una parte importante del diseño de las mismas. Hay universidades, por ejemplo la Pompeu Fabra de Barcelona, que propone que los alumnos desarrollen un sitio web informativo en internet, de acceso universal, sobre temas específicos. El caso del Diari de Barcelona (diaridebarcelona.cat) incide aún más en esa tendencia de la simulación profesional: se trata de un medio de comunicación real, de acceso libre a través de la web.

En todo caso, la ausencia de esa fortaleza nos indica una debilidad a tener en cuenta. Sin embargo, un $28 \%$ de las respuestas en primera opción, y un $19 \%$ de las tres opciones (principal fortaleza, segunda y tercera fortaleza), nos dicen que los docentes consideran que se trata de una "materia útil". Estas respuestas, aparentemente contradictorias, nos estarían indicando que los docentes consideran que la enseñanza del ciberperiodismo debería estar aún más enfocada al mercado laboral. Y, como debilidad tal vez significativa, una docente indica que en su caso "es una asignatura optativa" cuando debería ser obligatoria. El mapa de esas fortalezas más destacadas queda representado en la figura 1 y la tabla 5 .
Tabla 4. Percepción del profesorado sobre el interés de su asignatura

\begin{tabular}{|l|c|}
\hline Ningún interés & $0 \%$ \\
\hline Poco interés & $0 \%$ \\
\hline Moderado interés & $14 \%$ \\
\hline Bastante interés & $53 \%$ \\
\hline Mucho interés & $33 \%$ \\
\hline
\end{tabular}

En opinión de los docentes, se trata de asignaturas que deberían estar enfocadas al futuro ejercicio profesional y a formar periodistas digitales

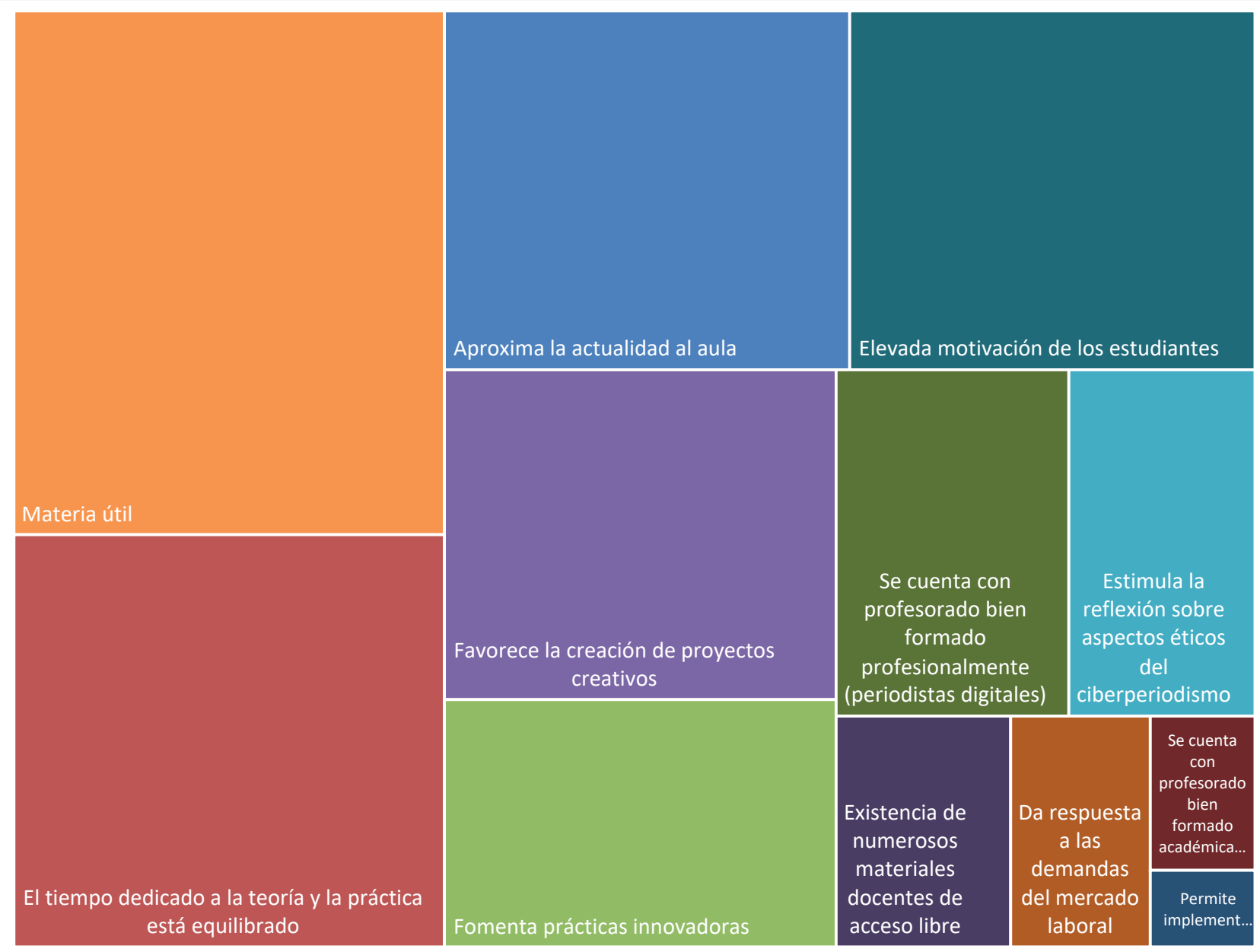

Figura 1. Percepción del profesorado sobre el interés de su asignatura 
Tabla 5. Percepción del profesorado sobre las principales fortalezas de la asignatura

\begin{tabular}{|c|c|}
\hline Por su experiencia, ¿cuál es la principal fortaleza de la disciplina? Respuesta única & Total \\
\hline Materia útil & 28 \\
\hline El tiempo dedicado a la teoría y la práctica está equilibrado & 22 \\
\hline Aproxima la actualidad al aula & 18 \\
\hline Elevada motivación de los estudiantes & 18 \\
\hline Favorece la creación de proyectos creativos & 16 \\
\hline Fomenta prácticas innovadoras & 12 \\
\hline Se cuenta con profesorado bien formado profesionalmente (periodistas digitales) & 10 \\
\hline Estimula la reflexión sobre aspectos éticos del ciberperiodismo & 8 \\
\hline Existencia de numerosos materiales docentes de acceso libre & 5 \\
\hline Da respuesta a las demandas del mercado laboral & 4 \\
\hline Se cuenta con profesorado bien formado académicamente (investigador) & 2 \\
\hline Permite implementar ejercicios de simulación profesionales & 1 \\
\hline Óptima capacitación del alumnado en el manejo de herramientas tecnológicas & 0 \\
\hline
\end{tabular}

La segunda fortaleza más destacada por los docentes es que esta asignatura ofrece un adecuado equilibrio entre la teoría y la práctica, como establece el escenario de los grados tras la reforma de Bolonia. Es una materia a la que sus docentes consideran que los estudiantes se acercan muy motivados, que aproxima a su vez la actualidad al aula, y fomenta prácticas innovadoras.
Otra de las fortalezas de la enseñanza del ciberperiodismo en España es que los estudiantes se acercan muy motivados, que aproxima a su vez la actualidad al aula, y fomenta prácticas innovadoras

La figura 2, que muestra un acumulado del peso otorgado a esas fortalezas en primera, segunda y tercera opción, nos presenta una visión más matizada de las respuestas.

En cuanto a las debilidades, la principal detectada por nuestra encuesta es que las materias vinculadas al ciberperiodismo requieren de una actualización constante por parte del docente: una quinta parte de las respuestas así lo atestigua. Este rasgo, en realidad, podría no ser una debilidad, sino una característica intrínseca por la propia naturaleza mutante de la materia docente y del periodismo en internet. Creemos que sería prudente interpretarlo así, aunque se haya in-

Óptima capacitación del alumnado en el manejo de...

Da respuesta a las demandas del mercado laboral

Elevada motivación de los estudiantes

Existencia de numerosos materiales docentes de acceso...

Se cuenta con profesorado bien formado...

Se cuenta con profesorado bien formado...

Permite implementar ejercicios de simulación profesionales

Materia útil

Estimula la reflexión sobre aspectos éticos del..

Favorece la creación de proyectos creativos

Fomenta prácticas in novadoras

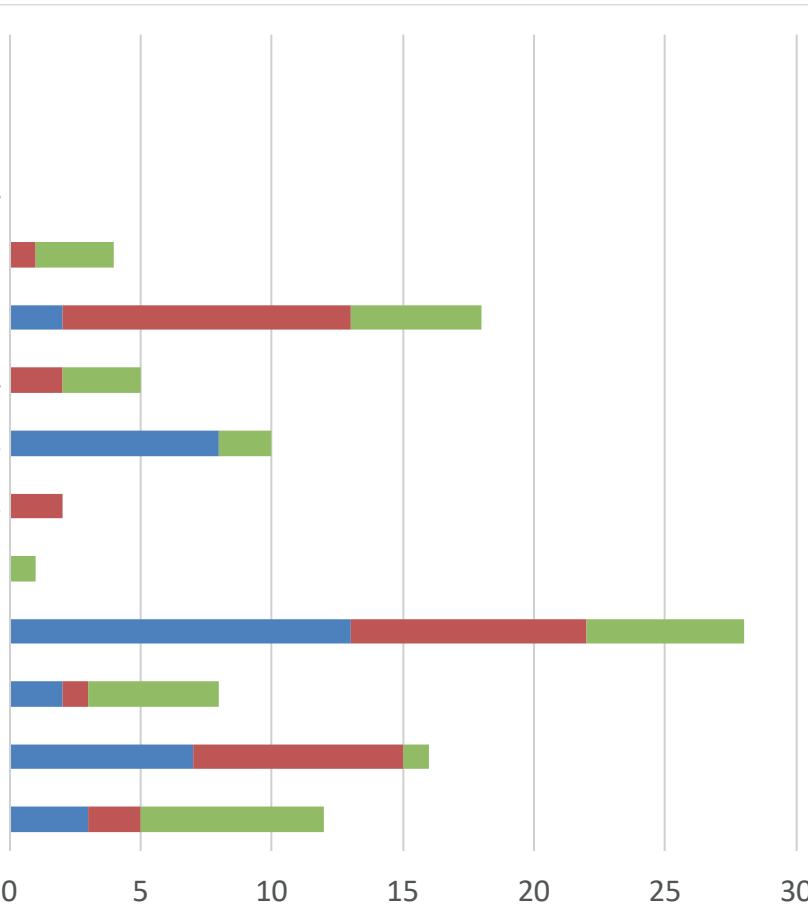

Primera fortaleza

- Segunda fortaleza

- Tercera fortaleza

Figura 2. Percepción del profesorado sobre las fortalezas de la asignatura, por opciones 
cluido en el diseño de la encuesta entre las debilidades. De hecho, el $89 \%$ de los docentes consultados asegura renovar estos programas cada curso, y el $11 \%$ restante dice hacerlo cada dos o tres años. Nadie mantiene los mismos contenidos durante más de tres cursos, en todo caso. Esta necesidad extendida de modificar el temario anualmente confirma que se trata, en realidad, de una peculiaridad de la materia. Esto contrasta, por supuesto, con otro tipo de asignaturas más clásicas, que requieren menos esfuerzo de actualización por parte de los docentes.

Ciberperiodismo todavía se percibe como una asignatura demasiado amplia, provocando cierta dispersión temática (un $17 \%$ de las respuestas), lo que, seguimos la respuesta literal de un participante de la encuesta,

“impide que todos los estudiantes puedan profundizar en todas las áreas (producto, diseño, edición, tecnológica)".

Dicho de otra manera: los contenidos propios de la materia se concentran en pocas asignaturas. Por lo tanto, se necesitaría bien incrementar el número de asignaturas para impartir los mismos contenidos, o bien reducir el volumen de contenidos para acomodarlo a las asignaturas existentes. La historia de la implantación de la enseñanza del ciberperiodismo nos indica que esta percepción corresponde a la realidad: las materias relacionadas con, sobre todo, la prensa, y luego la radio y la televisión, disponen de más asignaturas y más especializadas. Esto obedece a la propia juventud del periodismo en internet y a su reciente implantación en la universidad. Tengamos en cuenta que las respuestas de los encuestados así lo dicen: un $16 \%$ de los docentes cree que no es una disciplina suficientemente asentada en la Universidad, y un $7 \%$, que los docentes de otras asignaturas no ven las relacionadas con el ciberperiodismo como fundamentales, a pesar de la importancia creciente, al menos en términos de audiencia, de esta variedad periodística. La tabla 5 y la figura 3 permiten visualizar el peso otorgado por los docentes a cada opción.
La principal debilidad detectada es que las materias vinculadas al ciberperiodismo requieren de una actualización constante por parte del docente

Tabla 6. Percepción del profesorado sobre las principales debilidades de la asignatura

\begin{tabular}{|l|l|l|}
\hline Requiere la actualización permanente del docente & 24 & 21 \\
\hline Es una disciplina demasiado amplia, lo que implica una dispersión temática & 20 & 10 \\
\hline No es una disciplina suficientemente consolidada en la universidad & 10 \\
\hline No se cuenta con profesorado bien formado profesionalmente & 9 \\
\hline Masificación de las aulas, lo que dificulta la realización de prácticas & 9 \\
\hline Los compañeros docentes no la consideran fundamental & 8 & 7 \\
\hline Falta de infraestructuras para el desarrollo de las prácticas & 2 & 2 \\
\hline Está demasiado alejada de la realidad de las redacciones & \\
\hline Los estudiantes temen a las asignaturas tecnológicas & \\
\hline No se cuenta con profesorado bien formado académicamente & \\
\hline Escasa motivación de los estudiantes & \\
\hline
\end{tabular}

Otras debilidades mencionadas con cierta frecuencia son que no se cuenta con un profesorado bien formado profesionalmente (lo que ya se había detectado en las respuestas sobre fortalezas), y, por tanto, se necesitan más ciberperiodistas en ejercicio para impartir estos contenidos ( $8 \%$ de las respuestas), y que se trata, aseguran los docentes, de unas asignaturas alejadas de la realidad de las redacciones (7\%). Esta afirmación coincide con investigaciones anteriores, en las que estudiantes de Periodismo afirmaron que entre los docentes universitarios no existen profesionales formados en periodismo digital (Anaya; Laurencio; Aguirre, 2018).

Otras debilidades, percibidas como secundarias, son la falta de infraestructuras; el temor de los estudiantes a los contenidos tecnológicos; o la masificación de las aulas cuando se trata de materias que pretenden ser muy prácticas, orientadas a la formación de profesionales, que requieren el uso de equipamiento y, lo que es más importante, de metodologías docentes innovadoras que se basan en el aprendizaje más que en la enseñanza, con mayor acento en el alumno que en el profesor.

El manejo de herramientas tecnológicas no es una prioridad para los docentes de las asignaturas sobre ciberperiodismo en España. Es significativa la respuesta de un profesor de una asignatura obligatoria que indica que

"la realidad tecnológica en el periodismo (en la comunicación en general) avanza muy rápido; no así los estudios/ investigaciones (en cantidad y calidad) sobre esas realidades, lo que dificulta incorporarlas en el marco del proceso de enseñanza/aprendizaje". 


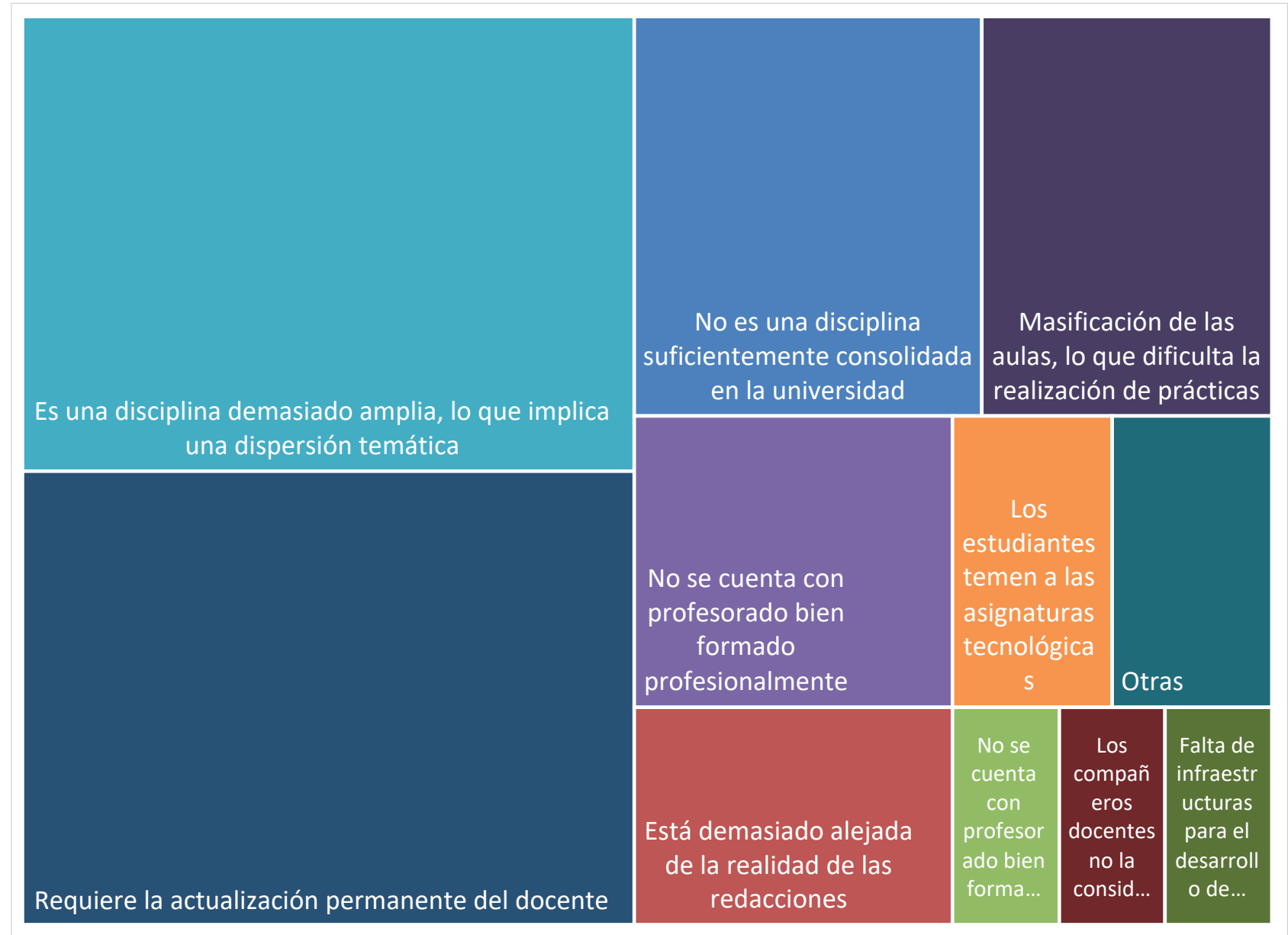

Figura 3. Percepción del profesorado sobre las debilidades de la asignatura, por opciones

\section{Otras}

Masificación de las aulas, lo que dificulta la realización...

Falta de infraestructuras para el desarrollo de las...

Escasa motivación de los estudiantes

Los compañeros docentes no la consideran fundamental

Requiere la actualización permanente del docente

Los estudiantes temen a las asignaturas tecnológicas

Es una disciplina demasiado amplia, lo que implica una..

No se cuenta con profesorado bien formado...

No se cuenta con profesorado bien formado...

Está demasiado alejada de la realidad de las redacciones

No es una disciplina suficientemente consolidada en la...
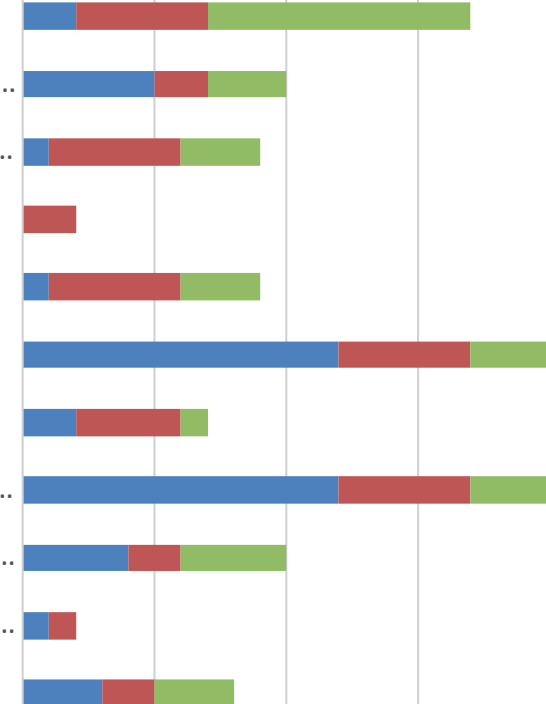

\section{- Primera fortaleza $\quad$ Segunda fortaleza $\quad$ Tercera fortaleza}


Y añade:

“Esto puede ocasionar que los alumnos requieran una actualización de la materia que, por la propia idiosincrasia del proceso investigador, no es posible".

Aun así, conviene que nos detengamos un tanto en esta cuestión: no faltan docentes que consideran que, a pesar de todo, se necesita una mejor base formativa del alumnado en las destrezas digitales -no necesariamente, aunque también, tecnológicas-, ni quienes detectan algunas carencias importantes. Uno de los profesores de 4으 cree que

"cada vez es más necesaria una mínima formación técnica (programación) que hoy en día puede ser asumida por estudiantes de humanidades y ciencias sociales".

Advierte de que

"hay una auténtica diferencia entre los estudiantes que comprenden los procesos tecnológicos y pueden establecer un diálogo con los desarrolladores técnicos y los que no".

Y concluye que

"el futuro está en la convergencia entre el área técnica y la humanística, manteniendo cierta especialización".

Hemos solicitado a la muestra de docentes que enumeren las herramientas y programas empleados en sus asignaturas. Es Wordpress, bien en su versión .org (profesional) o bien en su versión .com (de acceso libre), la plataforma más nombrada, porque facilita el acceso a un sistema de gestión de contenidos bien conocido, sobre el que abundan los manuales y tutoriales prácticos. En menor medida, también se emplean Blogger o Wix, y menos aún gestores o aplicaciones offline para el diseño de sitios web como Dreamweaver. Se van incorporando tímidamente las herramientas de Google News Initiative y las del Knight Lab de la Northwestern University en Chicago, Estados Unidos, entre ellas Juxtapose, TimeLine, Storymap o Storyline. https://knightlab.northwestern.edu

Se han descartado, prácticamente, los CMS (content management systems) propios, con una excepción: el Diari de Barcelona, cabecera que en 2019 el Ayuntamiento de Barcelona cedió en régimen de uso a los estudios de Periodismo de la Universitat Pompeu Fabra de Barcelona, y que emplea Liferay, sistema usado por todas las webs de esa universidad.

Se mencionan también, dentro de estas herramientas, todas las redes sociales: Twitter, Facebook, Instagram o YouTube, por ejemplo. Frente a ello, se emplean en ocasiones aplicaciones más especializadas, como DataWrapper, Infogram o Tableau para el desarrollo del periodismo de datos, Audacity o Adobe Audition para gestión de sonido (los podcasts se están revelando como una estrategia de éxito en los medios digitales estos últimos años, y se han incorporado a la docencia de ciberperiodismo), Photoshop para el tratamiento de imágenes, Geocommons, Sutori, Genial.ly o Wakelet, y naturalmente MailChimp, como servicio más intuitivo para confeccionar y enviar boletines informativos o newsletters, que han vuelto con fuerza en los últimos años.

\subsection{Expectativas de futuro del profesorado}

El futuro de los estudios de periodismo se construye a partir de la herencia recibida, de los estudios de periodismo, del nacimiento de la especialidad del periodismo digital en estas décadas, y a partir de la reordenación del campo periodístico. El hecho de que la tecnología digital acompañe al periodismo en el futuro, convirtiéndola en una cuestión transversal, no sólo no invalida la especialidad periodística nacida en el ciberespacio, sino que le abre nuevas perspectivas y muestra las caras de su complejidad (Eldridge II; Franklin, 2019). En un contexto determinado por la internet de las cosas, con la inteligencia artificial y la tecnología 5G como estandartes (Salaverría; De-Lima-Santos, 2020), la especialidad periodística para los medios matriciales y los medios nativos digitales se dirige a un escenario donde aumentará la demanda de formación específica que permita a los profesionales del periodismo elaborar piezas que aprovechen las potencialidades de las tecnologías actuales e impliquen a los usuarios de los entornos actuales, que alimentan los usos y consumos informativos.

Los rasgos diferenciales del ciberperiodismo (hipertextualidad, multimedialidad, interactividad), que han transformado las formas de hacer periodismo (Díaz-Noci, 2008), constituyen la columna vertebral de esta disciplina académica en el momento actual. Parece que también lo serán en el futuro. El estudio de esos rasgos, junto con la dotación de competencias y habilidades para su aplicación práctica, resulta decisivo para entender las dimensiones del periodismo digital, alrededor del que se han sedimentado teorías, métodos de investigación, plataformas y nuevas formas de relación con las audiencias. De ahí que los estudios de periodismo digital constituyen un campo interdisciplinario que va más allá de las tradiciones de los estudios de periodismo (Steensen; Westlund, 2020).

Actualmente, mientras actores tradicionales y periféricos del espacio mediático adoptan principios periodísticos (Holton; Belair-Gagnon, 2018), hay muchos actores periféricos que están pasando a ser fundamentales (Hermida; Young, 2019), aunque no formen parte de las instituciones típicamente asociadas a las definiciones dominantes del periodismo y su 
industria (Deuze, 2019). Este panorama de mutaciones aconseja superar los marcos referenciales de la disciplina en el pasado (Deuze; Witschge, 2020) y una revisión del campo periodístico en la que la especialidad del periodismo digital desempeña un papel destacado. La formación en las competencias y habilidades introducidas por esos nuevos actores está asociada a la especialidad del periodismo digital, lo que exigirá la incorporación no solo de contenidos transversales en varias materias, sino la creación de materias específicas.
Nos dirigimos a un escenario donde aumentará la demanda de formación específica que permita a los profesionales del periodismo elaborar piezas que aprovechen las potencialidades de las tecnologías actuales (hipertextualidad, multimedialidad, interactividad) e impliquen a los usuarios

Los resultados de la encuesta, sobre todo en forma de respuestas abiertas, con la que hemos consultado al profesorado de las asignaturas de ciberperiodismo sugieren una reflexión crítica del escenario actual, que probablemente marcará el futuro de esta disciplina, sobre todo a partir del momento en que el relevo generacional en la universidad española sea una realidad. Hay quienes consideran que la situación actual "precisa un cambio en el itinerario del plan de estudios", pero también existen declaraciones más contundentes, como la de esta profesora de 4 o de Periodismo:

"Avanzar colisiona con la realidad burocrática y jerárquica de la universidad. No existen procesos de renovación de planes de estudios ágiles, lo que unido a la falta de diálogo en el seno de algunas facultades provoca la pervivencia de estructuras, planes de estudios y programas estáticos, clásicos y primitivos. Existe por defecto una resistencia al cambio y a aplicar enfoques innovadores, lo que frena la evolución natural que sí se observa en el entorno profesional. La ausencia de autocrítica y la apuesta por soluciones que no incomoden son el mal de nuestra universidad".

En las reflexiones de los docentes hemos detectado una doble forma de enfrentar la docencia del ciberperiodismo en el futuro. Por una parte, la de quienes defienden incrementar el número de asignaturas para desarrollar adecuadamente sus diferentes vertientes: técnica, redaccional, ética y de diseño, entre otras. Por otra parte, la de quienes defienden un crecimiento basado en la transversalidad de las áreas y especialidades. La expansión de la digitalización ha provocado que varios docentes se cuestionen hasta qué punto tiene sentido segregar las materias por medios de comunicación, como si fuesen compartimentos estancos:

"La enseñanza del periodismo digital no creo que deba estudiarse hoy en día como algo específico. El periodismo es ya digital, es una realidad global que debe estar integrada en la enseñanza del periodismo como algo natural",

asegura un docente. Esta otra respuesta de un profesor sintetiza esta postura, que cuenta ya con una relativa fuerza en los estudios de Comunicación:

“Considero que el periodismo digital debe integrarse en asignaturas más globales (comunicación), en donde se abarque todo lo que comporta las labores de comunicación... que no son estrictamente periodísticas: SEO, analítica, edición/medición de Twitter, Instagram, podcasts, cibermedios, etc. Además, la temática ya no es solo la producción periodística clásica (noticias y otros géneros "de siempre"), sino que amplía su temática: experimentos sociales, comparativas de realidades físicas o virtuales, encuestas (físicas o virtuales), diseños de ránkings, historias de vida (de personajes que han vivido tal situación), elaboración de directorios... Toda esta nueva amplitud temática requiere el conocimiento de nuevas tecnologías de la comunicación".

"O se es digital o no se es", concluye otro encuestado. Frente a eso, se detecta una cierta resistencia al cambio, lógica si se quiere, debido a la diferente procedencia, edad ("Ios profesores más mayores no le dan la importancia que tiene") y formación del profesorado. También en los medios: una profesora señala que

"las redacciones son muy herméticas a la hora de compartir con el mundo académico sus dinámicas actuales de trabajo";

por tanto, se necesitaría una mejor sinergia con la empresa informativa. En este sentido, es significativo el empleo de manuales de tipo práctico sobre periodismo móvil.

“El periodismo digital no tiene vuelta atrás, por lo que todo el periodismo es/será digital, pero se precisará la especialización para los productos que centren su estrategia en el escenario de la sociedad red y para los soportes que convivan y compitan en este escenario",

sentencia un catedrático.

Por otra parte, en opinión de los docentes de ciberperiodismo, en muchos casos pioneros en la investigación y la docencia de esta disciplina, debería ser una materia todavía más orientada al perfil profesional, a la práctica y más coordinada con el mundo profesional.

"Una parte muy importante -por su actividad y peso en la nota final-, es que cada curso, los estudiantes deben

fundar, redactar, promocionar y gestionar una revista digital",

explica un profesor de otra asignatura obligatoria. A ello se añaden preocupaciones como los objetivos de desarrollo sostenible (ODS). 
Otra tendencia es apostar por la creación de iniciativas derivadas (spin-offs) a partir de las asignaturas generales sobre ciberperiodismo. Sin embargo, esos emprendimientos se perciben claramente insuficientes, a causa de la diversidad de aspectos que explicar en muy pocas horas. Un ejemplo es el periodismo de datos, cuyo aprendizaje requiere la laboriosa tarea de familiarizarse con la programación.

Por su propia formación, los docentes más experimentados en la materia se han centrado en aspectos como la redacción de noticias para la web o el diseño digital. Los manuales que se emplean para la impartición de la asignatura así lo reflejan. De forma bastante mayoritaria, el manual todavía de referencia, aunque no pocos docentes han matizado que se van necesitando otros contenidos más actualizados, es el Manual de redacción ciberperiodística de 2003, coordinado por Javier Díaz-Noci y Ramón Salaverría, y que en aquel momento, hace casi veinte años, reunió a los primeros profesores de la materia.

"Es muy difícil encontrar un manual, artículos científicos y capítulos de libros más actuales",

sintetiza una profesora que imparte clase en 3 de Periodismo.

"No hay manuales actualizados y que estén adaptados al 100\% de la asignatura",

critica. Como resultado lógico, los docentes tienden a emplear capítulos de libro o artículos para los aspectos concretos del temario. Esto tiene que ver también con el propio enfoque, más actual, de las asignaturas universitarias, sobre todo las que, como esta y al menos en el aspecto técnico -probablemente no tanto por lo que respecta a otros más relacionados con los valores y prácticas de la profesión-, necesitan de una actualización casi continua. Lo que, a su vez, añade dificultad a las materias sobre ciberperiodismo, con la constante aparición de nuevas herramientas de edición, diseño, o de redes sociales, que hay que aprender a manejar y cuya investigación sobre los efectos profundos que puedan ejercer en la profesión es más lenta de lo que requiere la enseñanza universitaria.

Por abundar algo más en los materiales empleados, junto al manual ya mencionado, se emplean otros como Redacción periodística en Internet, de Ramón Salaverría; Periodismo en Internet: cómo escribir y publicar contenidos de calidad en la red, de Gabriel Jaraba, que fue periodista y profesor de la Universitat Autònoma de Barcelona; o Los géneros en la redacción ciberperiodística: Contexto, teoría y práctica actual, de Larrondo-Ureta (2009); y contenidos en inglés (Siapera; Veglis, 2012; Larrondo; Meso; Tous, 2014; Burum; Quinn; 2015; Stewart, 2017; Galan; Osserman; Parker; Taylor, 2019). Otros materiales mencionados ocasionalmente en la encuesta, todos ellos en castellano, y además de manuales puramente técnicos de herramientas concretas, son los de Tascón (2012), García-de-Torres (2012), García-Avilés (2015), Noguera-Vivo (2015), Salaverría (2016), Sanagustín (2017), Nafría (2017), y Pérez-Soler (2017).

\section{Conclusiones}

Este estudio sobre la enseñanza universitaria del periodismo digital, periodismo en internet o ciberperiodismo -la nomenclatura es todavía diversa- en las universidades españolas, elaborado mediante un análisis documental y una encuesta a los profesores que impartían esta materia en el curso 2020-2021, nos ha permitido constatar la consolidación de esta especialidad mediante las materias obligatorias y optativas que figuran en los planes de estudio vigentes. Las sucesivas renovaciones y actualizaciones han hecho posible que los cambios introducidos en la oferta hayan ido más allá de los contenidos transversales en los descriptores de buena parte de las materias y que se haya incrementado notablemente la oferta de materias -un 32,5\% en comparación con el mapa de cinco años atrás-. Los datos recogidos en esta investigación indican que, en el curso 2020-2021, el número de asignaturas relacionadas con el ciberperiodismo superaba el centenar (119) y que la práctica totalidad de las facultades de Comunicación españolas (38 de 40 ) había incorporado alguna materia de esta especialidad.

La consolidación académica de esta disciplina no es meramente cuantitativa, también se refleja en la categoría alcanzada por sus asignaturas. En un contexto de expansión de los contenidos relacionados con lo digital, más del $63 \%$ de las asignaturas vinculadas al periodismo digital en los actuales planes de estudio de Periodismo tienen carácter obligatorio. Aunque no hay coincidencia en la estrategia de las diferentes universidades españolas, se advierten tres tendencias claras:

- centros que apuestan por aproximaciones más teóricas;

- centros que optan por un enfoque más práctico, mediante la creación de proyectos multimedia estrechamente relacionados con la actividad profesional, y, finalmente,

- centros que impulsan materias orientadas a nuevos perfiles profesionales (preferentemente datos, programación web o gestión de la información en redes sociales). 
El proceso de cambio en la oferta docente de materias de ciberperiodismo también está acompañado de iniciativas que auspician la innovación en el campo de la metodología docente, especialmente en lo relacionado a mejorar la confianza y la relación mutua entre los alumnos que realizan un proyecto y los profesores que lo coordinan.

Es importante dejar constancia de que el ciberperiodismo se ha consolidado como uno de los campos considerados con mayor potencial en la actualidad para promover la innovación profesional, investigadora y docente (Larrondo-Ureta; Peña-Fernández; Fernandes-Teixeira, 2021). A pesar de eso, la relativa juventud de la materia hace que la mayor parte del profesorado señale importantes aspectos de mejora en las asignaturas y en el conjunto de los planes de estudio, donde las expresiones digitales del periodismo continúan infrarrepresentadas. Mientras la investigación sobre ciberperiodismo es una disciplina afianzada y en desarrollo, con desafíos metodológicos y temáticos que deberá afrontar en los próximos años (Salaverría, 2019), la enseñanza muestra algunas debilidades, que el propio profesorado señala, como hemos visto. El panorama cambiante de la educación y la tecnología ha impulsado la creación de un nuevo marco de referencia, a su vez, para la educación superior en el contexto digital, que incluye como compañeros de viaje a los nuevos, o tal vez ya no tan nuevos, medios (Strawser, 2017). En la medida en que la industria se halla en transición (Díaz-Noci, 2021), la academia detecta nuevas tendencias en la investigación y nuevas características a explorar (Costera-Meijer; Rogers; Westlund; Witschge, 2021). A su vez, profesionales, empresarios (editores) y audiencias coinciden en que la pervivencia de un periodismo de calidad depende de la integración del entorno tecnológico, el económico y el de los principios esenciales de la profesión (Marta-Lazo; Rodríguez-Rodríguez; Peñalva, 2020). La aparición de nuevos perfiles profesionales a los que la formación universitaria debe adaptarse, requiere de una menor resistencia a los cambios en la universidad, con un incremento de profesionales de los medios que transfieran en el aula su experiencia con las habilidades necesarias para la práctica profesional actual.

\section{Limitaciones}

No queremos acabar este apartado de conclusiones sin referirnos a las obvias limitaciones de este artículo y, por eso mismo, a la necesidad de más y mejor investigación futura sobre los aspectos docentes. La primera limitación de nuestro estudio es que, a pesar del apartado dedicado a la historia de la enseñanza del ciberperiodismo, no se trata de un estudio longitudinal, sino llevado a cabo en un momento preciso. Creemos necesario realizar estudios similares que nos permitan obtener una serie de conclusiones en un periodo de tiempo mayor, de manera que las tendencias que ahora se vislumbran en nuestro análisis se revelen como duraderas o efímeras. Un estudio longitudinal nos permitiría también comprobar hasta qué punto el cuerpo docente mantiene o no las percepciones que se han manifestado en esta investigación puntual, y hasta qué punto las fortalezas se han afianzado y si las debilidades se han corregido.

La segunda limitación es inherente a los métodos utilizados. Por dos razones. La primera, que las técnicas empleadas sirven para obtener resultados principalmente descriptivos. Para profundizar en el análisis de los fenómenos, se necesitarán otros métodos; por ejemplo, entrevistas semiestructuradas con determinados perfiles de docentes involucrados en la enseñanza del ciberperiodismo, así como de profesores de otras disciplinas más alejadas, para evaluar también su opinión. La segunda razón es que, si bien consideramos que los resultados de la encuesta son satisfactorios y nos han permitido detectar lo que buscábamos, hubiese sido deseable un mayor nivel de respuesta, y por tanto de representatividad sobre el universo estudiado. Probablemente todo ello hace que este estudio sólo pueda ser exploratorio. No es poco, en cualquier caso, y confiamos por tanto en su utilidad.

\section{Nota de los autores}

1. Dedicamos este trabajo a la memoria de nuestro compañero Pere Masip, pionero e impulsor de la investigación sobre ciberperiodismo, fallecido el 18 de julio de 2021, durante la ejecución de esta investigación.

\section{Referencias}

Anaya, María-del-Pilar; Laurencio, Rossy; Aguirre, Patricia-del-Carmen (2018). “De lo análogo a lo digital. Necesidades tecnológicas en la enseñanza del ciberperiodismo". En: Navarro-Zamora, Lizy (coord.). "Miradas del ciberperiodismo en Iberoamérica". Cuadernos artesanos de comunicación, n. 143, pp. 115-130.

http://www.cuadernosartesanos.org/2018/cac143.pdf

Armañanzas, Emiliana; Díaz-Noci, Javier; Meso-Ayerdi, Koldobika (1996). El periodismo electrónico: información y servicios multimedia en la era del ciberespacio. Barcelona: Ariel. ISBN: 9788434412705

Bierhoff, Jan; Schmidt, Mogens (eds.) (1997). European journalism training in transition: the inside view. Maastricht: European Journalism Centre. https://pure.uva.nl/ws/files/2050671/26461_jt.pdf

Boczkowski, Pablo J. (2004). Digitizing the news. Innovation in online newspapers. Cambridge Mass.: The MIT Press. ISBN: 9780262268844

https://doi.org/10.7551/mitpress/2435.001.0001

Brainard, Curtis (2010). "The man who imagined tablets and e-readers. An interview with Roger Fidler of the RJI Digital Publishing Alliance". Columbia journalism review, June 17.

https://archives.cjr.org/behind_the_news/fidler_q_and_a.php 
Burum, Ivo; Quinn, Stephen (2015). MoJo: The mobile journalism handbook: How to make broadcast videos with an iPhone or iPad. Waltham: Focal Press. ISBN: 9781138824898

Castells, Manuel (1996). The information age: Economy, society and culture. Volume I: The rise of de network society. Cambridge, MA: Blackwell. ISBN: 9780631221401

Costera-Meijer, Irene; Rogers, Richard; Westlund, Oscar; Witschge, Tamara (2021). Researching the news in the hybrid media system: an expert panel report. In: Díaz-Noci, Javier; Serrano-Telleria, Ana (eds.). Barcelona: Universitat Pompeu Fabra. Departament de Comunicació.

http://hdl.handle.net/10230/47055

Davenport, Thomas; Beck, John C. (2001). The attention economy: Understanding the new currency of business. Massachusetts: Harvard Business School Publishing. ISBN: 9781578518715

Deuze, Mark (2001). "Online journalism: Modelling the first generation of news media on the World Wide Web". First Monday, v. 6, n. 10.

https://doi.org/10.5210/fm.v6i10.893

Deuze, Mark (2004). “What is multimedia journalism?”. Journalism studies, v. 5, n. 2, pp. 139-152. https://doi.org/10.1080/1461670042000211131

Deuze, Mark (2019). "What journalism is (not)". Social media + society, v. 5, n. 3, pp. 1-4. https://doi.org/10.1177/2056305119857202

Deuze, Mark; Witschge, Tamara (2020). Beyond journalism. Cambridge, UK: Polity Press. ISBN: 9780745643410

Díaz-Noci, Javier (1994). "El nuevo periódico electrónico. Redefinición del mensaje periodístico tradicional como producto interactivo y multimedia”. En: IX Jornadas internacionales de ciencias de la información: la revolución de las audiencias, organizadas por la Facultad de Ciencias de la Información de la Universidad de Navarra, Pamplona, 10 y 11 de noviembre de 1994.

Díaz-Noci, Javier; Meso-Ayerdi, Koldobika (1998). “Desarrollo del periodismo electrónico". Profesional de la información, v. 7, n. 12, pp. 4-11.

http://www.elprofesionaldelainformacion.com/contenidos/1998/diciembre/desarrollo_del_periodismo_electronico.html

Díaz-Noci, Javier; Meso-Ayerdi, Koldobika (2000). Periodismo electrónico multimedia. Bilbao: Servicio Editorial de la Universidad del País Vasco. ISBN: 8475857124

Díaz-Noci, Javier (2013). "History of journalism on the Internet: A state of the art and some methodological trends". Revista internacional de historia de la comunicación, v. 1, n. 1, pp. 253-272.

http://institucionales.us.es/revistarihc/documentos/rihc-01-articulo-12.pdf

Díaz-Noci, Javier; Meso-Ayerdi, Koldobika (1999): Periodismo en internet. Modelos de la prensa digital. Bilbao: Servicio Editorial de la Universidad del País Vasco. ISBN: 9788483731614

Díaz-Noci, Javier (2005). “Historia de los cibermedios en España”. En: Salaverría, Ramón (coord.). Cibermedios. El impacto de internet en los medios de comunicación en España (pp. 21-38). Sevilla: Comunicación Social Ediciones y Publicaciones. ISBN: 9788496082335

Díaz-Noci, Javier; Salaverría, Ramón (coords.) (2003). Manual de redacción ciberperiodística. Barcelona: Ariel. ISBN: 978 8434412972

Díaz-Noci, Javier (2008). "Definición teórica de las características del ciberperiodismo: elementos de la comunicación digital". Doxa comunicación, n. 6, pp. 53-91.

https://doi.org/10.31921/doxacom.n6a2

Díaz-Noci, Javier (2021). The life of news and the wealth of media companies in the digital world: Reader revenues and professional practices in a post-Covid world. Barcelona: Universitat Pompeu Fabra. Departament de Comunicació, 27 pp. (Serie editorial DigiDoc. DigiDoc reports).

http://hdl.handle.net/10230/46349

Eldridge II, Scott; Franklin, Bob (eds.) (2019). The Routledge handbook of developments in digital journalism studies. London: Routledge. ISBN: 9781138283053

Fidler, Roger (1981). "Videotex services will become mature businesses". In: Newspapers in the year 2000. A special report published by the Associated Press Managing Editors Association. [s.I.]: Associated Press Managing Editors Association.

https://www.syracuse.com/future-news/2010/03/roger_fidlers_1981_essay_videotex_services_will_become_mature_ businesses.html 
García, Mario R. (1998). Redesigning print for the web. Indiana: Hayden Books. ISBN: 9781568303437

García-Galera, María-del-Carmen; Martínez-Nicolás, Manuel; Del-Hoyo-Hurtado, Mercedes (2021). "Innovation in journalism educational programmes at university. A systematic review of educational experiences at Spanish universities". Profesional de la información, v. 30, n. 3, e300307.

https://doi.org/10.3145/epi.2021.may.07

García-Avilés, José-Alberto (2015). Comunicar en la sociedad red. Barcelona: UOC. ISBN: 9788490646052

García-de-Torres, Elvira (2012). Cartografía del periodismo participativo. Valencia: Tirant Humanidades. ISBN: 97884 15442189

Hermida, Alfred; Young, Mary-Lynn (2019). "From peripheral to integral? A digital-born journalism not for profit in a time of crises". Media and communication, v. 7, n. 4, pp. 92-102.

https://doi.org/10.17645/mac.v7i4.2269

Holton, Avery E.; Belair-Gagnon, Valerie (2018). "Strangers to the game? Intralopers, and Shifting news production". Media and communication, v. 6, n. 4, pp. 70-78.

https://doi.org/10.17645/mac.v6i4.1490

IJIE Integrated journalism in Europe is an Erasmus lifelong learning project (2014). Journalism higher education in Europe. Barcelona, Paris, Copenhague, Cluj-Napoca, Lund: Pompeu Fabra University, Paris 8 Vincenne-Saint Dennis University, Danish School of Media and Journalism, Babes-Bolay University, Linnaeus University.

http://integratedjournalism.upf.edu/wp-content/uploads/2015/06/Journalism-Higher-Education-in-Europe-DBbookJANUARY.pdf

Jaraba, Gabriel (2014). Periodismo en Internet: cómo escribir y publicar contenidos de calidad en la red. Barcelona: Robinbook. ISBN: 9788415256694

Katz, Jon (1999). The future is the net. Media studies journal, v. 13, n. 2.

Larrondo-Ureta, Ainara (2009). Los géneros en la redacción ciberperiodística: Contexto, teoría y práctica actual. Leioa: Servicio Editorial de la Universidad del País Vasco. ISBN: 9788498601763

Larrondo-Ureta, Ainara; Meso-Ayerdi, Koldobika; Tous-Rovirosa, Anna (coords). (2014). Shaping the news online: A comparative research on international quality media. Covilhã: LabCom. ISBN: 9789896541521

Larrondo-Ureta, Ainara; Canavilhas, João; Fernandes-Teixeira, Juliana; Luiz-Martins, Gerson; Meso-Ayerdi, Koldobika; Pérez-Dasilva, Jesús; Peña-Fernández, Simón; Zamith, Fernando (2020). "Innovación educativa para la internacionalización y la convergencia de la enseñanza del ciberperiodismo en Iberoamérica”. Anàlisi: Quaderns de comunicació $i$ cultura, n. 62, pp. 35-56.

https://doi.org/10.5565/rev/analisi.3264

Larrondo-Ureta, Ainara; Peña-Fernández, Simón; Fernandes-Teixeira, Juliana (2021). “Online journalism teaching and learning processes beyond the classroom and the university: Experiences in international virtual collaboration on multimedia projects". Journalism \& mass communication educator, v. 76, n. 1, pp. 5-28.

https://doi.org/10.1177/1077695820916620

López-García, Xosé (2010). "La formación de los periodistas en el siglo XXI en Brasil, España, Portugal y Puerto Rico". Revista latina de comunicación social, n. 65, pp. 231-243.

https://doi.org/10.4185/RLCS-65-2010-896-231-243

Marinho, Sandra; Sánchez-García, Pilar (2020). "Historia de la enseñanza del periodismo en España y Portugal: una línea de tiempo con paralelismos y contrastes". Cuadernos.info, n. 47.

https://doi.org/10.7764/cdi.47.1781

Marta-Lazo, Carmen; Rodríguez-Rodríguez, Jorge-Miguel; Peñalva, Sheila (2020). “Digital journalism competences. Systematic review of the scientific literature on new professional profiles of the journalist". Revista latina de comunicación social, n. 75, pp. 53-68.

https://www.doi.org/10.4185/RLCS-2020-1416

Martínez-Arias, Santiago M.; Parra-Valcarce, David (2020). "E-innovation platforms in journalism teaching: Cybermedia as a professional education tool". Communication \& society, v. 33, n. 4, pp. 123-136.

https://doi.org/10.15581/003.33.4.123-136

Masip, Pere; Micó-Sanz, Josep-Lluís (2010). "Investigación sobre ciberperiodismo en España. Trayecto hacia la consolidación”. Profesional de la información, v. 19, n. 6, pp. 577-584.

https://doi.org/10.3145/epi.2010.nov.03 
Molina, Alfonso (1999). "Transforming visionary products into realities: Constituency-building and observation in NewsPad". Futures, v. 31, n. 3-4, pp. 291-332. https://doi.org/10.1016/S0016-3287(98)00135-9

Murciano-Martínez, Marcial (coord.) (2005). Libro blanco. Títulos de grado en comunicación. Madrid: Aneca. http://www.aneca.es/var/media/150336/libroblanco_comunicacion_def.pdf

Nafría, Ismael (2017). La reinvención del New York Times. [s.I.]: CreateSpace Independent Publishing Platform. ISBN: 978 1544822792.

Noguera-Vivo, José-Manuel (2015). Todos, todo: manual de periodismo, participación y tecnología. Barcelona: UOC. ISBN: 9788491160380

Oggolder, Christian; Brügger, Niels; Metyková, Monika; Salaverría, Ramón; Siapera, Eugenia (2020). “The emergence of the Internet and the end of journalism?". In: Arnold, Klaus; Preston, Paschal; Kinnebrock, Susanne. The handbook of European communication history. Hoboken, NJ: Wiley Blackwell. ISBN: 9781119161622

Palomo, Bella (2004). El periodista on line: de la revolución a la evolución. Sevilla: Comunicación Social. ISBN: 97884 92860067

Palomo, Bella (2017). Proyecto docente e investigador. Málaga: Universidad de Málaga. Proyecto presentado por Bella Palomo al concurso oposición de profesora catedrática.

Palomo, Bella; Sánchez, María (2014). "El reto de formar a periodistas participativos: reflexiones docentes". Historia y comunicación social, febrero, v. 19, n. extra 2, pp. 465-478.

https://doi.org/10.5209/rev_HICS.2014.v19.45042

Pavlik, John V. (2001). Journalism and new media. New York: Columbia University Press. ISBN: 9780231114837

Pavlik, John V. (2004). "A sea-change in journalism: Convergence, journalists, their audiences and sources". Convergence, v. 10, n. 4, pp. 21-29.

https://doi.org/10.1177/135485650401000404

Pérez-Luque, María-José; Perea, Maider (1997). El actual periodismo online. São Paulo: Mirandum. http://www.hottopos.com/MirLibro

Pérez-Soler, Susana (2017). Periodismo y redes sociales. Claves para la gestión de contenidos digitales. Barcelona: UOC. ISBN: 9788491169864

Salaverría, Ramón (2005). Redacción periodística en Internet. Pamplona: Eunsa. ISBN: 9788431322595

Salaverría, Ramón (2009). "El MMLab: Explorando el futuro". En: Vidal-Quadras, José-Antonio; López-Escobar, Esteban (eds.). Fcom: 50 años preparando el futuro, pp. 122-123. Pamplona: Ediciones Universidad de Navarra. ISBN: 97884313 26258

Salaverría, Ramón (2016). “España”. En: Salaverría, Ramón (coord.). Ciberperiodismo en Iberoamérica, pp. 170-209. Madrid: Fundación Telefónica y Editorial Ariel. ISBN: 9788408154525

Salaverría, Ramón (2019). “Digital journalism: 25 years of research. Review article". Profesional de la información, v. 28, n. 1, e280101.

https://doi.org/10.3145/epi.2019.ene.01

Salaverría, Ramón; De-Lima-Santos, Mathias-Felipe (2020). "Towards ubiquitous journalism: impacts of loT on news". In: Vázquez-Herrero, Jorge; Direito-Rebollal, Sabela; Silva-Rodríguez, Alba; López-García, Xosé (eds.). Journalistic metamorphosis: Media transformation in the digital age, pp. 1-15. Cham: Springer International Publishing. https://doi.org/10.1007/978-3-030-36315-4_1

Sanagustín, Eva (2017). Plan de contenidos para medios sociales. Barcelona: UOC. ISBN: 9788490293607

Sánchez-Duarte, José-Manuel; Fernández-Romero, Diana (2015). “Pensar con la acción. Aprendizaje por proyecto en la enseñanza del periodismo digital”. Opción, v. 31, n. especial 5, pp. 856-870.

https://doi.org/10.7764/cdi.48.27827

Sánchez-García, Pilar (2017). Periodistas (in)formados. Madrid: Universitas. ISBN: 9788479914783

Sánchez-García, Pilar (2021). Proyecto docente e investigador. Valladolid: Universidad de Valladolid. Proyecto presentado por Pilar Sánchez-García al concurso oposición de profesora titular.

Siapera, Eugenia; Veglis, Andreas (eds.) (2012). The handbook of global online journalism. Oxford: Wiley-Blackwell. ISBN: 9781118313978 
Smith, Anthony (1983). The newspaper revolution of the 1980's. Oxford / New York: Oxford University Press. ISBN: 978 0192159533

Steensen, Steen; Westlund, Oscar (2020). What is digital journalism studies. London: Routledge. ISBN: 9780367200909

Stewart, Peter (2017). The live-streaming handbook: How to create live video for social media on your phone and desktop. NewYork: Routledge. ISBN: 9781138630048

Strawser, Michael G. (ed.) (2017). New media and digital pedagogy: Enhancing the twenty-first-century classroom (Studies in new media). Lanham, Boulder, New York, London: Lexington Books. ISBN: 9781498548519

Tascón, Mario (dir.) (2012). Escribir en Internet. Guía para los nuevos medios y las redes sociales. Barcelona: Galaxia Gutenberg. ISBN: 9788415472087

Teixeira, Juliana; Larrondo-Ureta, Ainara (2016). “Estratégias de formação dos ciberjornalistas no contexto das redações convergentes e 2.0: A simulação de ambientes profissionais através de ID126 (Brasil) e RedaCCiber (Espanha)". Opción, n. 80, pp. 36-65.

https://doi.org/10.13140/RG.2.2.19492.73605

Tejedor-Calvo, Santiago (2006). La enseñanza del ciberperiodismo en las licenciaturas de periodismo de España. Tesis doctoral. Barcelona: Universitat Autònoma de Barcelona.

Tejedor-Calvo, Santiago (2007). La enseñanza del ciberperiodismo: de la alfabetización digital a la alfabetización ciberperiodística. Zamora: Comunicación Social Ediciones y Publicaciones. ISBN: 9788496082465

\section{Anexo}

\section{Cuestionario empleado en la encuesta}

Título: El periodismo digital en la universidad española

1. Categoría académica

Doctor/a | No doctor/a

2. Si es doctor, ¿Cuánto hace que obtuvo el grado de doctor?

Menos de 2 años | De 3 a 5 años | 6 o más años

3. Condición académica

Permanente | No permanente

4. ¿Es usted el profesor principal de la asignatura?

Sí | No

5. ¿En qué curso imparte la asignatura?

1 | 2 | 3 | 4

6. ¿Qué tipo de asignatura es?

Obligatoria | Optativa

7. ¿Cuántos años lleva impartiendo está asignatura u otras relacionadas con el periodismo digital?

Menos de 5 años | Entre 6 y 10 años | Más de 11 años

8. Qué participación tiene usted en el diseño de la asignatura, del 0 al 5, siendo 0 ninguna participación, y 5 participación completa.

$1|2| 3|4| 5$

9. ¿Con qué frecuencia actualiza los contenidos de la asignatura?

Anualmente | Cada 2-3 años

10. Mencione tres herramientas/aplicaciones que considere fundamentales para los proyectos desarrollados por sus estudiantes en su asignatura.

[Campo abierto]

11. En caso de recomendar algún manual de referencia, ¿podría indicar al menos dos?

[Campo abierto]

12. En una escala del 1 al 5, siendo 1 ninguno y 5 mucho, valore el interés de la asignatura entre sus estudiantes

$1|2| 3|4| 5$ 
13. Por su experiencia, ¿̇cuál es la principal fortaleza de la disciplina? [Respuesta única]

\begin{tabular}{|l|}
\hline a. Aproxima la actualidad al aula \\
\hline b. El tiempo dedicado a la teoría y la práctica está equilibrado \\
\hline c. Fomenta prácticas innovadoras \\
\hline d. Favorece la creación de proyectos creativos \\
\hline e. Estimula la reflexión sobre aspectos éticos del ciberperiodismo \\
\hline f. Materia útil \\
\hline g. Permite implementar ejercicios de simulación profesionales \\
\hline h. Se cuenta con profesorado bien formado académicamente (investigador) \\
\hline i. Se cuenta con profesorado bien formado profesionalmente (periodistas digitales) \\
\hline j. Existencia de numerosos materiales docentes de acceso libre \\
\hline k. Elevada motivación de los estudiantes \\
\hline I. Da respuesta a las demandas del mercado laboral \\
\hline m. Óptima capacitación del alumnado en el manejo de herramientas tecnológicas \\
\hline
\end{tabular}

14. ¿Y la segunda fortaleza? [Respuesta única, misma lista]

15. ¿Y la tercera? [Respuesta única, misma lista]

16. Por su experiencia, ¿cuál es la principal debilidad de la disciplina? [Respuesta única]

a. No es una disciplina suficientemente consolidada en la universidad

b. Está demasiado alejada de la realidad de las redacciones

c. No se cuenta con profesorado bien formado académicamente

d. No se cuenta con profesorado bien formado profesionalmente

e. Es una disciplina demasiado amplia, lo que implica una dispersión temática. :

f. Los estudiantes temen a las asignaturas tecnológicas

g. Requiere la actualización permanente del docente

h. Los compañeros docentes no la consideran fundamental

i. Escasa motivación de los estudiantes

j. Falta de infraestructuras para el desarrollo de las prácticas

k. Masificación de las aulas, lo que dificulta la realización de prácticas

17. ¿Y la segunda debilidad? [Respuesta única, misma lista]

18. ¿Y la tercera? [Respuesta única, misma lista]

19. Valore de 1 a 5 , siendo 1 muy en desacuerdo y 5 muy de acuerdo, las afirmaciones siguientes sobre el futuro del periodismo digital en la universidad

a. Cada vez tendrán más peso en los planes de estudio

b. Tenderán a desaparecer, integrándose en asignaturas más generales y transversales

c. Aumentar la especialización incluyendo a docentes del área de ingeniería informática para programación, creación de chatbots.

d. Revisar los currículos académicos de manera permanente

e. La expansión de la inteligencia artificial reducirá la oferta y la demanda de los estudios de Periodismo

20. Para finalizar, y si lo desea, puede aportar cualquier información adicional sobre el futuro de la enseñanza del periodismo digital que considere que no haya quedado reflejado en la encuesta.

[Respuesta abierta] 